Portland State University

PDXScholar

7-18-1980

\title{
A Comparison of Three Measures of Waking Fantasy
}

Carey Sue Edney

Portland State University

Follow this and additional works at: https://pdxscholar.library.pdx.edu/open_access_etds

Part of the Cognition and Perception Commons

Let us know how access to this document benefits you.

Recommended Citation

Edney, Carey Sue, "A Comparison of Three Measures of Waking Fantasy" (1980). Dissertations and Theses. Paper 3011.

https://doi.org/10.15760/etd.2988

This Thesis is brought to you for free and open access. It has been accepted for inclusion in Dissertations and Theses by an authorized administrator of PDXScholar. Please contact us if we can make this document more accessible: pdxscholar@pdx.edu. 
AN ABSTRACT OF THE THESIS OF. Carey Sue Edney for the Master of Science in Psychology presented July 18, 1980.

Title: A Comparison of Three Measures of Waking Fantasy.

APPROVED.BY MEMBERS OF THE THESIS COMMITTEE:

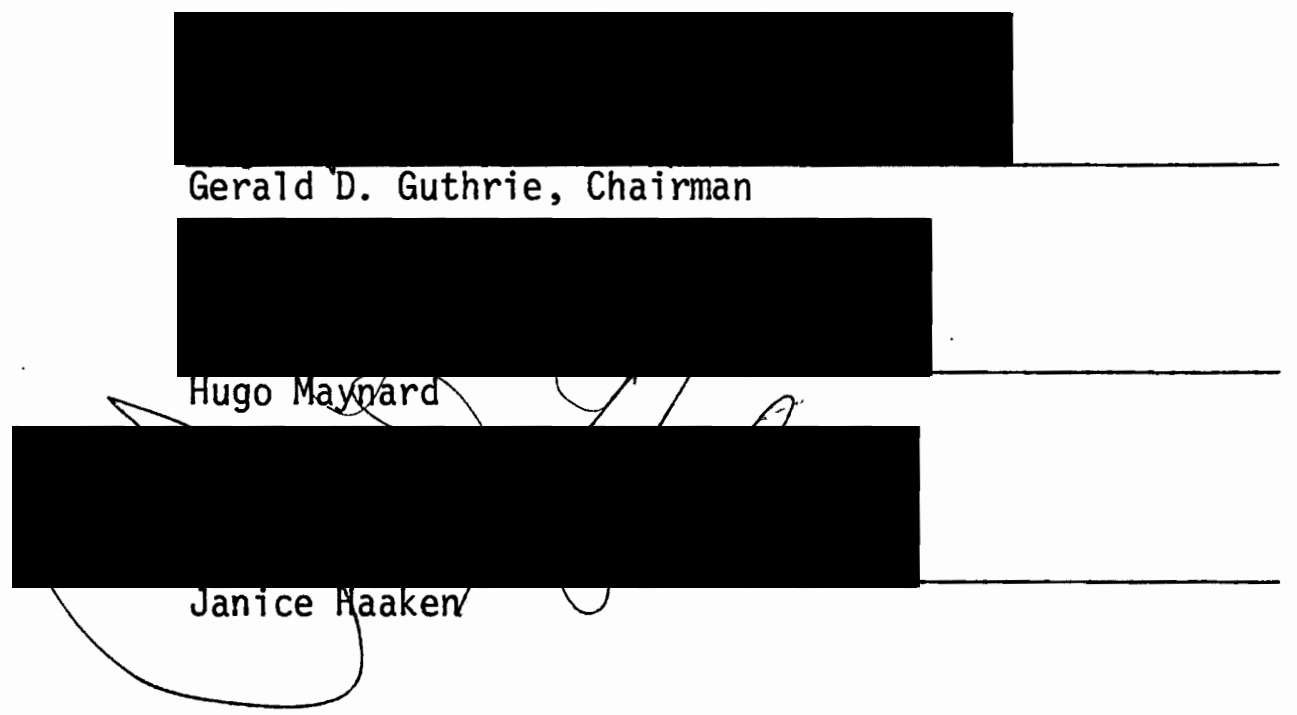

This project compared three techniques of assessing waking fantasy, or daydreaming. The Thematic Apperception Test (TAT), the Imaginal Processes Inventory (IPI), and time-sampled ongoing mentation reports (OMR) were the three measures employed. Seven qualities were compared, as measured by the three methods, using a multitraitmultimethod correlation matrix. Neither extensive convergent nor extensive discriminant validity was demonstrated among the three measures. This suggests that one should use caution in comparing research findings which utilize different measures of waking fantasy.

A portion of the methodology of this study replicated that of an earlier study. Time-sampled ongoing mentation reports yielded 
hallucinatory mentation and loss of contact with reality in the waking state. The findings of the present study paralleled those of the original study. As in the original study, the findings suggest that: (1) hallucination occurs in the waking state more frequently than has been assumed, and (2) reality contact is not an appropriate criterion for the distinction between waking and sleeping mentation. 
A COMPARISON OF THREE MEASURES OF WAKING FANTASY

by

CAREY SUE EDNEY

A thes is submitted in partial fulfillment of the requirements for the degree of

\author{
MASTER OF SCIENCE \\ in \\ PSYCHOLOGY
}

Portland State University

1980 
TO THE OFFICE OF GRADUATE STUDIES AND RESEARCH:

The members of the Committee approve the thesis of Carey Sue Edney presented July 18, 1980.

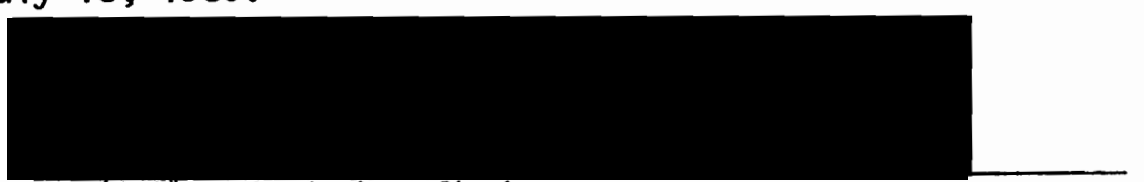

Gerald'D. Guthrie, Chairman

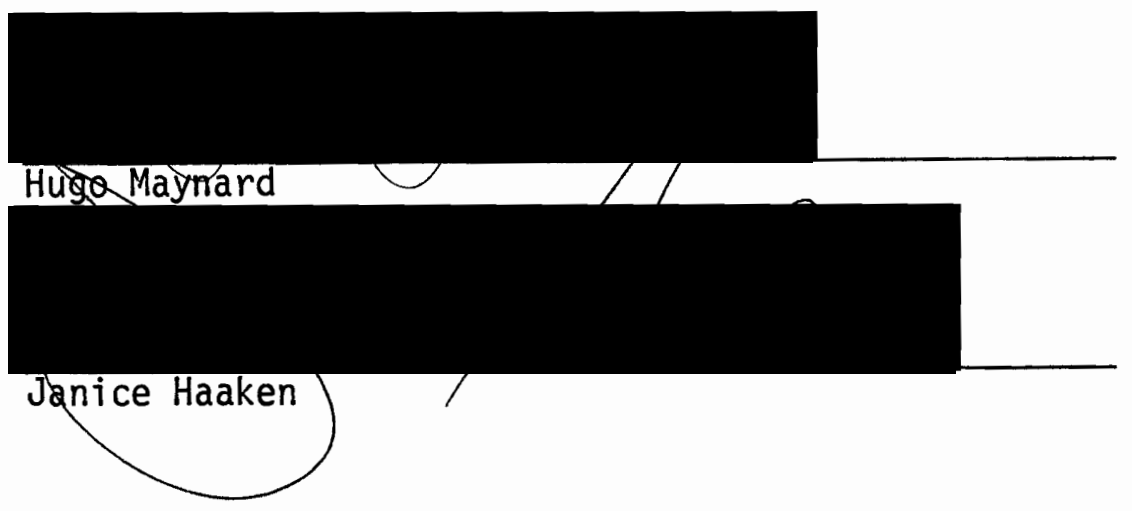

APPROVED:

Robert E. Jones, Jr., Head Department of Psychology

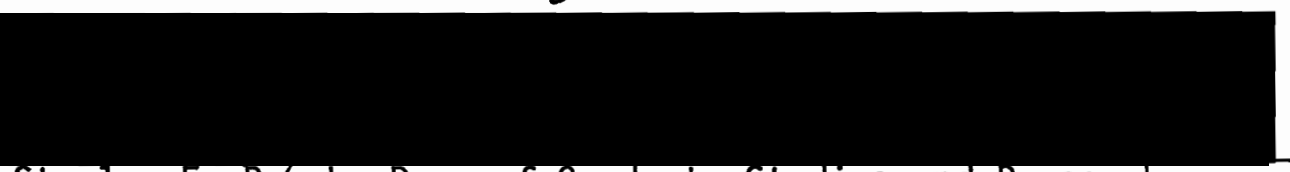

Stanley E. Ratrch, Dean of Graduate Studies and Research 
TABLE OF CONTENTS

PAGE

ACKNOWLEDGMENTS

LIST OF TABLES

LIST OF FIGURES

INTRODUCTION .

II METHODOLOGIES OF SLEEP RESEARCH . . . . . . . •

Psychophysiological Method . . . . . . . .

Dream Diaries ............. . . 6

II METHODOLOGIES IN THE ASSESSMENT OF WAKING FANTASY .

Psychophysiological Method . . . . . . .

Questionnaire ............ .

Projective Tests . . . . . . . . . . .

IV THREE MODELS OF THE RELATION BETWEEN DAYDREAMING AND NIGHT DREAMING

Alternative Channels ............

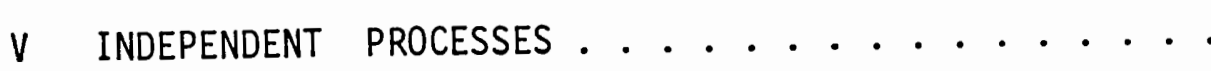

VI CONTINUUM MODEL . . . . . . . . . . . . 26

VII A DESCRIPTION OF THE PRESENT STUDY ..........

Statement of Purpose . . . . . . . . .

Method ............... .

Subjects

Procedures 
CHAPTER

VIII RESULTS ..................

Comparison of the Three Different Measures . . . . 52

IX DISCUSSION OF RESULTS ............... 59

Replication of the Foulkes and Fleisher Study . . 60

Comparison of the Three Different Measures . . . 61

Means and Standard Deviations of the Three Measures

Comparison of the Present Results with Normative Data on the IPI

Convergent and Discriminant Validity on the Multitrait-Multimethod Matrix Consideration of Previous Research in Light of the Present Results

$X$ SUMMARY AND CONCLUSIONS

REFERENCES ........................

A ORIENTATION SCRIPT--OMR ............ . 84

B INTERVIEW-OMR .............. 86

C REGRESSIVITY--OMR ............ 87

D REALITY CONTACT-OMR .................. 88

E RATING SCALE FOR EMOTIONAL TONE--OMR AND TAT . . . . 89

F. RATING SCALE FOR OUTCOME--OMR AND TAT . . . . . . 90

G RATING SCALE FOR ACHIEVEMENT, AGGRESSION, AND

SEX--OMR AND TAT ................ 91

H RATING SCALE FOR BIZARRENESS--OMR AND TAT . . . . . 93

I RATING SCALE FOR VIVIDNESS--OMR AND TAT . . . . . . 94

J IMAGINAL PROCESSES INVENTORY SCALES . . . . . . . 95

$K$ COMPARISONS TO BE MADE BETWEEN CODED CATEGORIES

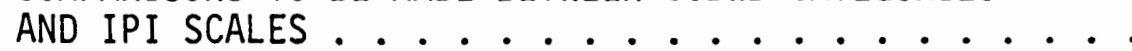




\section{LIST OF TABLES}

TABLE

PAGE

I Reliability of Judges' Ratings of Regressivity . . . .

II Reliability of Judges' Ratings of Reality Contact . . .

III Comparison of Present Results with Those of Foulkes

and Fleisher: Hallucinatory and Endogenous

Imagery . . . . . . . . . . . . . .

IV Comparison of Present Results with Those of

Foulkes and Fleisher: Patterns of Reality Contact.

$V$ Comparison of Present Results with Those of Foulkes

and Fleisher: Regressivity and Patterns of

Reality Contact ..............

VI Chi ${ }^{2}$ Analysis of the Incidence of Regressive and Hallucinatory Mentation . . . . . . . . .

VII Multitrait-Multimethod Correlation Matrix: Seven

Traits by Three Methods . . . . . . . . .

VII Summary List of Significant Correlations . . . . . .

IX Reliability of Judges' Ratings for Each Trait in Terms of Pearson's $\underline{r}:$ OMR and TAT .........

$X$ Mean and Standard Deviation for Each Trait: OMR,

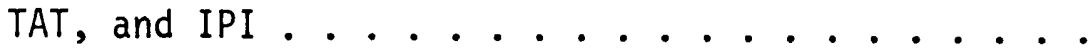

XI IPI Means and Standard Deviations: Comparison of

Present Results with Normative Data ...... 58

XII Factor Loadings of IPI Scales on Three Second-Order Factors. 


\section{LIST OF FIGURES}

FIGURE

PAGE

1. Simplified Multitrait-Multimethod Correlation Matrix Adapted from Campbe11 and Fiske (1959) . . . . . . 


\section{ACKNOWLEDGMENTS}

Special thanks are due Jerry Guthrie, Hugo Maynard, and Jan Haaken for their support of this research effort. Without them this exploration into the nature of daydreaming would not have happened. Jan Haaken performed a particularly valuable service in elucidating the nature of psychoanalytic theory. Along with Dr. George Lendaris, the committee members are to be further commended for their willingness to process drafts within the rigid time constraints of my personal situation.

Thanks are also due to Dr. Jerome Singer and Dr. George Huba for their willingness to share their thoughts and their unpublished data.

I also wish to acknowledge and express my appreciation to the following persons: Joan Anderson (for enduring my compulsivity), Brian Hebener (for many long hours at the computer terminal), Jim Paulson (for advice on statistical and philosophical matters), Katherine Brown and Laura Sheppard (for rating the OMR and TAT with efficiency and care), Lynn Hockaden (for technical advice on manuscript preparation and for drive), and the subjects who participated in the study (for their willingness to share large parts of themselves with me).

Finaliy, words cannot express the importance of the support given me by my husband, Bill Hupprich, throughout weeks of neglect. 


\section{CHAPTER I}

\section{INTRODUCTION}

The study of subjective inner experience is currently enjoying a reemergence in academic psychology (Holt, 1964; K1inger, 1972; Ornstein, 1972; Sheehan, 1972; Singer, 1966; Singer, 1975; Tart, 1972; Tomkins, 1962). Several factors have lent support to a growing body of research into such phenomena as hallucination and other types of endogenous sensory imagery, memory processes, night dreaming, and daydreaming. Such practical problems as the pernicious hallucinations accompanying the extended monotonous perceptual stimulation of jet pilots and astronauts have created a demand for research into subjective phenomena. Additional credence to such research efforts can be attributed to the discovery of physiological correlates of altered states of consciousness, including the contributions of psychopharmacology and sleep research (Holt, 1964). Thus, having abandoned the study of such "mentalistic" phenomena in the early part of this century, many psychologists are now turning attention to the construction of theoretical models of cognition which can account for the occurrence of vivid, internally stimulated experiences.

The construction of theoretical models has given rise to methodological questions which are sometimes ignored by researchers. Such appears to be the case with regard to studies of the relationship between daydreaming and night dreaming. Proponents of various theoretical 
models of this relationship have used a variety of techniques to assess the two states. The results of research are difficult to compare due to this use of divergent methodologies.

This project was designed to compare three techniques of assessing waking fantasy, or daydreaming, leading to a consideration of that body of research which attempts to elucidate the relationship between daydreaming and night dreaming. The Thematic Apperception Test (TAT), the Imaginal Processes Inventory (IPI), and time-sampled ongoing mentation reports (OMR) were the three measures employed in this study. Seven qualities of fantasy production, as assessed by the three different methods, were compared.

A second study was conducted in conjunction with this one (Anderson, 1980). This second study, hereafter referred to as Study II, focused on right-left hemisphere activation and dominance in visual and verbal imagery. The methodology presented here includes a description of all Study II procedures, since the same subjects served in both studies. The measures used for Study II were the Betts Questionnaire of imagery vividness, the Gordon Questionnaire of image controllability, and a paired-associate learning task (PAL). Study I and Study II shared certain data from the OMR.

An acquaintance with the methodologies of previous research is presented before describing the methodology of the current project. Following this description, three current models of the relationship between waking and sleeping mentation are presented in order to set the stage for discussion of the results of this study. Finally, the 
methods and results of this study are presented and discussed, along with suggestions for future explorations into the nature of daydreaming. 
CHAPTER II

METHODOLOGIES OF SLEEP RESEARCH

PSYCHOPHYSIOLOGICAL METHOD

The pioneering work of Aserinsky and Kleitman (1953) established the method of sleep research which is most widely recognized today. These researchers inadvertently discovered the occurrence of periods of rapid eye movements (REM) during sleep. These REM periods occurred in a cyclical pattern in conjunction with low-voltage, mixed brain-wave frequencies, similar to the waking EEG. Further, it was found that subjects awakened during these REM periods typically reported perceptually vivid dreams. "For the first time in history, a reliable, objective, quantifiable index of the occurrence of dreams seemed to be available" (Arkin, 1978, p. 2). Further research has yielded discovery of other physiological characteristics of REM sleep, including massive inhibition of muscular activity potential and penile erections (Arkin, 1978). Non-REM (NREM) sleep also yields dream-like mentation, but less frequently than REM sleep. NREM reports are typically more conceptual than perceptual (i.e., verbal vs. sensory, especially visual).

Using the physiological correlates mentioned above, researchers began to obtain mentation reports from REM and NREM stages of sleep to determine psychological correlates of the two types of sleep. Mentation reports are usually obtained by awakening the subject by calling his/her name over an intercom, or by using a buzzer or tone. The experimenter 
then asks the subject to report what was going through his/her mind just before the awakening (Foulkes, Spear, and Symonds, 1966). The experimenter questions the subject according to a format standardized for all subjects in that particular experiment. These questions usually involve the sensory qualities of the dream, the vividness of imagery, affective tone, personal involvedness, and bizarreness (Foulkes, Spear, and Symonds, 1966).

The reports obtained from subjects using the above procedure are coded for various stylistic, affective, and content categories. Most coding systems involve a scale on which the report is rated by independent judges. One of the most frequently used stylistic systems is the Dreamlike Fantasy Scale (DF Scale) developed by Foulkes (Foulkes, 1971). This scale consists of a seven-point scale ranging from no content $(0$ points) to perceptual content which is hallucinatory, bizzare or unusual, and dramatic ( 7 points). This scale has proven reliable with values ranging from .81 to .99 (Cartwright, 1972; Cartwright, Monroe, and Palmer, 1967; Foulkes, Spear, and Symonds, 1966). An adaptation of this scale, used in this study, is located in Appendix I.

An interesting series of experiments comparing sleep onset mentation with waking fantasy, REM, and NREM reports, have led to the development of rating scales for two ego functions: (1) maintaining nonregressive content, and (2) maintaining contact with external reality (Foulkes, Spear, and Symonds, 1966; Foukes and Vogel, 1965; Voge1, Foulkes, and Trosman, 1966). Judgment of regressivity is a yes-no decision based on the presence of at least one of six qualities of mentation ranging from single, isolated images to magical or omnipotent thinking. 
Reality contact judgment consists of three yes-no decisions on the following qualities of mentation: (1) ability to distinguish between an internal and an external event; (2) awareness of location in space and time; and (3) control over the progression of thoughts. This coding system has been applied to waking fantasy in a study described later with $95 \%$ agreement between two independent judges (Foulkes and Fleisher, 1975). Vogel's scales were used in the present study and are located in Appendices $C$ and $D$.

\section{DREAM DIARIES}

This procedure simply involves the subject writing down his/her dreams upon awakening, which means that the qualities of the dream available for coding are based on the subject's recall of dream material after some time has elapsed. This procedure is obviously less timeconsuming and costly than laboratory methods. It has been used extenSively by David Cohen (Cohen, 1969; Cohen, 1972; Cohen, 1973). He argues that dream diaries are highly predictive of laboratory recall (Cohen, 1974). In support of this, research has shown that some nonrecallers report "dream-1ike" mentation significantly less frequently than recallers when awakened in a laboratory situation (Goodenough, Shapiro, Holden, and Steinschriber, 1959). However, it has been pointed out that the dream remembered upon awakening may be unrepresentative in that it is usually derived from the last REM period, and is likely to be more lengthy, bizarre, and exciting than dreams reported from earlier REM periods (Cartwright and Kaszniak, 1978). 
Dream reports obtained by this method have been scored according to the same methods as are described above for reports of psychophysiologically monitored subjects. 


\section{CHAPTER III}

\section{METHODOLOGIES IN THE ASSESSMENT OF WAKING FANTASY}

\section{PSYCHOPHYSIOLOGICAL METHOD}

This method parallels that used for sleep research. The first published use of this method occurred in 1975, with Foulkes and Fleisher's report of some findings which surprised them (Foulkes and Fleisher, 1975). Based on an earlier incidental finding in connection with an unpublished project, these researchers attached electrodes to twenty young adults to monitor EEG and EOG (electrooculogram). Each subject then lay down in a moderately illuminated room for one hour under instructions to "relax, but stay awake" (Foulkes and Fleisher, 1975, p. 67). The experimenters, isolated from the subject, interrupted the subject at six randomly selected times and asked for a report of the subject's last presignal mental experience. The subject had been told that the purpose of the research was to establish a waking baseline of response to a structured interview which was designed for use in sleep research. The experimenters were "generally apologetic" about asking subjects to apply this interview to their waking thought, and were warned that portions of the interview schedule might not be applicable to waking thought. The reports thus obtained were coded for regressivity and reality contact, as described earlier in this paper. Since the present study replicated Foulkes and Fleisher's study, the 
questions and categories of this coding system, as well as the script used to orient the subjects, are included in Appendices $A, B, C$, and D. Of 120 arousals, 118 yielded a report of presignal mentation. Endogenous visualization was reported on $78(68 \%)$ of 115 arousals on which subjects said their eyes were closed before hearing the signal. Endogenous auditory imagery was reported on $18(16 \%)$ of the 111 arousals on which subjects reported being unaware of incidental noise in the laboratory. Of the 78 endogenous visualization reports, 12 occurred with auditory imagery. On 6 occasions, only auditory imagery was reported. This yielded 84 arousals in which some form of endogenous imagery was reported. of these reports, $23(27 \%)$ were judged hallucinatory in quality. That is, the subject reported that he/she felt that during the experience, the events which he/she imagined were really happening. Of the total reports of mentation (118), 19\% were of this hallucinatory quality.

As previously mentioned, the content of the reports was coded for regressivity and reality contact. Twenty-five percent of the reports were judged regressive, and $62 \%$ showed some loss of contact with reality. Fifteen percent were judged to be totally lacking in reality contact, i.e., the subject "is not controlling his thoughts, he is not aware he is in the laboratory, and his mentation is hallucinatory" (Foulkes and Fliesher, 1975, p. 69).

The authors concluded that previous research into the nature of waking fantasy had underestimated the occurrence of hallucination and loss of ego function in the waking state, and further that traditional distinctions between daydreaming and night dreaming may need to be 
reconsidered. Specifically, the study indicated that the waking baseline of hallucinatory mentation is well above $0 \%$ and that the criterion of reality testing may not be useful as a descriptor of the difference between daydreaming and night dreaming.

\section{QUESTIONNAIRE}

Jerome Singer and John Antrobus have developed the Imaginal Processes Inventory to assess waking fantasy (Singer and Antrobus, 1972). A series of studies has refined the instrument to 28 scales which assess various aspects of daydreaming (Segal, Huba, and Singer, 1980; Singer, 1966; Singer and Antrobus, 1963; Singer and McCraven, 1962; Singer and Schonbar, 1961).

The IPI consists of 344 items which are responded to on a 5-point Likert-type scale. Of the 28 subscales, 27 deal with imaginal processes. Seven of the scales are measures of curiosity and patterns of attention. The items from the scales are randomized in order of presentation. A list of the 28 scales is included in Appendix $\mathrm{J}$, since the present study used this questionnaire.

Singer and Antrobus (1972) administered this test to 206 college students, along with the Maudsley Personality Inventory, California Psychological Inventory, and the Stein-Craik Activity Preference Inventory. Their purpose was to establish some additional normative data on the newly revised instrument. A total of 64 variables were scored and entered into a correlation matrix. Factor analysis yielded nine factors accounting for $56 \%$ of the total variance. Examination of the factor loadings yielded three characteristic styles of daydreaming: 
(1) Anxious-distractible. This style included those subjects who scored high on measures of distractibility, worry, absorption in daydreaming, poor sense of well-being, mind wandering, and anxiety.

(2) Guilty-dysphoric. This style consisted of those subjects who engaged in tortured self-concern, doubt, ethical rumination, fantasies of achievement, failure, and heroism with a great deal of negatively toned emotional content.

(3) Positive-vivid. This style included those subjects who engaged in frequent, vivid, and absorbing daydreams which they viewed positively. Content was oriented toward the future. A high degree of interpersonal curiosity was characteristic of the Positive-vivid style.

These styles have consistently emerged from factor analytic studies and are considered valid reflections of enduring daydream styles by the researchers who have used the measure (Singer and Antrobus, 1963; Singer and McCraven, 1961; Singer and McCraven, 1962; Starker, 1973; Starker, 1974). A shortened form of the IPI is currently being developed which is based on three second-order factors very similar to the three daydreaming styles described above (Huba, Aneshensel, and Singer, 1980).

\section{PROJECTIVE TESTS}

The projective tests which have been used to assess waking fantasy fall into two general categories: semi-structured story-telling tests, e.g., the Thematic Apperception Test (Murray, 1938), and the 
more ambiguous ink blot tests, e.g., the Rorschach or Holtzman Ink Blot tests.

The most frequently used measure obtained from ink blot tests is the Human Movement response to the Rorschach series. Rorschach described a type of response which involved perception of humans in action (Rorschach, 1942). He felt that this response to the ink blot, if repeated throughout the series of cards, was correlated with a tendency for the individual to be relatively inhibited in motor activity and given to reflectiveness or attention to inner life (Singer, 1955; Singer, 1960). With respect to dream research, this measurement has been taken as a measure of the tendency to resort to fantasy and has been found to increase in some REM-deprived subjects (Cartwright and Ratzel, 1972). Page (1957) found that subjects who reported high daydream frequency on a questionnaire also showed more $M$ responses than subjects who reported low daydream frequency. Barron (1955) reported that persons rated by observers as imaginative showed a tendency to produce more $M$ responses. Finally, Singer (1955; 1960) reported that inhibition of overt motor response was positively correlated with increased $M$ response as well as with TAT imaginativeness.

TAT stories have been coded on a number of categories. In research relating fantasy production to such variables as overt behavior, dreams, and personality variables, these stories have been coded for aggression, sexual content, achievement themes, transcendence, and hedonistic tone, among other themes (Fiss, Klein, and Bokert, 1966; Foulkes and Rechtschaffen, 1964; Foulkes, Spear, and Symonds, 1966; Gordon, 1950; Gordon, 1953; Kagan, 1956; Murray, 1938; Pivik and Foulkes, 
1968; Sarason, 1944; Singer and Rowe, 1962; Weisskopf, 1950). In dream research, the scores on content categories from TAT stories are compared to scores on the same categories derived from dream reports. The dream reports may be obtained by either of the above mentioned methods (psychophysiological or dream diary).

A number of stimulus and situational variables have been found to influence TAT stories. Relevant to the present study are the issues of ambiguity and emotional tone of the stories generated, instructions to the subject, and effect of the experimenter's reaction to the stories.

Murstein (1961) reports that stimulus ambiguity relates to the amount of projection a subject employs in a curvilinear fashion, as opposed to the linear relationship assumed to hold for all projective techniques. The idea of the traditional approach is that the more ambiguous the stimulus, the more a subject must project his own inner dynamics into the structure of his story. In contrast, Murstein (1961) suggests that a curvilinear relationship exists, i.e., cards of medium ambiguity elicit more themes than cards which are either high or low in ambiguity. Murstein further reports that highly ambiguous cards elicit significantly more pleasant themes (Murstein, 1961). Due to these findings, the TAT cards to be used in this study were of moderate ambiguity, as reported by Bijou and Kenney (1951). Additionally the cards were selected to elicit a variety of themes, according to the normative data provided by Eron (1950).

Another consideration was that of the instructions given to the subject prior to administration of the cards (Murstein, 1963). For 
example, significant differences in reporting sexual content were found between groups of subjects given different instructions regarding the degree of emotional adjustment reflected by controlled story production (Lubin, 1960; Lubin, 1961). Therefore, the subjects of the present study received instructions which contained no reference to the purpose of the test. The subjects were simply asked to write a story about each card (see methodology section of this paper for full details of administration).

The final consideration taken into account in the design of this study involved individual versus group administration. The traditional administration involves showing individual subjects each card and asking for a verbal report of a story (Murray, 1938; Murray, 1943). Subtle non-verbal and verbal reactions to the stories by the experimenter can potentially influence the subject's stories (Murstein, 1963).

Group administration involves asking the subjects to write a story in response to each card, thus precluding the experimenter's knowledge of and reaction to the stories. Group administration yields shorter stories and more rejections of cards (i.e., subject does not write a story) (Murstein, 1963). However, Murstein (1963) points out that content is not significantly different between stories of different word counts. None of the subjects in this study rejected any of the cards. 


\section{CHAPTER IV}

\section{THREE MODELS OF THE RELATION BETWEEN DAYDREAMING AND NIGHT DREAMING}

Researchers have postulated three models of the relationship between waking and sleeping mentation: (1) alternative channels, (2) independent processes, and (3) continuum (Cartwright, 1978; Singer, 1966; Starker, 1974; Voge1, 1978). Chapters IV, V, and VI are devoted to the description of each model, including mention of the techniques used by relevant studies to assess the two states of consciousness.

\section{ALTERNATIVE CHANNELS}

This model is based on Freud's topographical model of the mind (Freud, 1915/1935). The topographical aspect involves the relative contribution of the unconscious, the preconscious, and the conscious realms of the mind. The unconscious contains repressed conflicts and wishes, and the preconscious blends "day residue" with the unconscious dream material to create a blend of dream elements which is palatable to the dreamer's conscious mind.

This theory is also a developmental theory, in that the personality structures which are responsible for the control of topographical movement develop in a predictable sequence as the person grows from infancy. The id and the energy it contains (1ibido and destructive instincts) are present at birth and are considered to generate the 
dream material, as well as psychosis and, in fact, all thought. The ego develops to negotiate the demands of the id with reality, and derives its energy from the id. The superego develops as the child begins to incorporate as his own the demands of the parents and of "the family, racial and national traditions handed on through them [the parents], as well as the demands of the immediate social milieu which they [the parents] represent" (Freud, 1949/1969). The ego must also negotiate the demands of the superego with reality and with the demands of the id.

An action by the ego is as it should be if it satisfies simultaneously the demands of the id, of the super-ego and of reality --that is to say, if it is able to reconcile their demands with one another... the id and the super-ego have one thing in common: they both represent the influences of the past--the id the influence of heredity, the super-ego the influence, essentially, of what is taken over from other people--whereas the ego is principally determined by the individual's own experience, that is by accidental and contemporary events. (Freud, 1949/1969)

During the waking state, the ego maintains control over the expression of psychic energy. All psychic energy is derived from the id, which Freud called the "true psychic reality." This reference is made because the "id represents subjective inner experience and has no knowledge of reality" (Hall and Lindzey, 1970, p. 32). When some internal or external stimulation causes an increase in tension, the id immediately seeks to reduce the tension. This is referred to as the pleasure principle. The increase in tension is referred to as a drive.

The id can reduce tension through reflex action, such as sneezing or blinking, or through primary process. Primary process operates to reduce tension by forming an image, or hallucination, of the object which, in reality, can reduce the state of tension. The partial release of tension thus obtained by primary process enables the person 
to delay gratification of the drive and reduces the tendency for the person to engage in physical movement. For example, the hungry infant can partially reduce the tension of hunger by hallucinating an image of his mother's breast. "The image itself, in its hallucinated form, has a temporarily satisfying value, and the child gradually learns that it need not thrash around in violent restlessness or fruitless crying" (Singer, 1975, p. 103). Primary process is the stuff of dreams, as well as of psychotic thought processes. For the non-psychotic adult, dreams provide a release of unconscious conflicts, which, if made conscious, would be unacceptable to the ego, or superego.

The organism will not survive for long if primary process is the only method of drive reduction. Thus, the ego develops in order to negotiate between the demands of the id and external reality. The ego operates according to the reality principle. It develops the capacity to transfer and invest energy from the id into external objects which can satisfy drives. This reinvestment of energy in external objects is called object-cathexis. This process represents the two ego functions assessed by Vogel et al. (Vogel, Foulkes, and Trosman, 1966): (1) maintaining reality contact, and (2) control over regressive (hallucinatory, unrealistic) thought quality.

During sleep, the ego relinquishes to some extent the investment of energy in external reality. Thus, unconscious material can press into awareness in the form of a dream. This is possible because the dreamer is effectively inhibited from overt expression of the unconscious material. Dreaming thus serves as a forum for the release of energy contained in the unconscious, including object-cathexes which 
may be unacceptable to the waking ego or superego. For example, the person may desire to reduce his sexual drive through intercourse with an object-cathexis, perhaps his mother, which is socially taboo. While awake, the ego can reinvest this energy into a more appropriate objectcathexis, and the inappropriate object-cathexis is repressed into the unconscious. With the withdrawal of cathexes of the ego, however, primary process provides a forum for the expression of repressed objectcathexes. This way of gratification of a drive is called wish fulfillment. In the dream it is the dream wish.

Because the system described above is a closed system, any tension, or psychic energy, released during dreaming is thus diverted from alternate modes of expression. That is, the level of tension is reduced and therefore the press for conscious awareness and for action to alleviate the tension is reduced. The drive will be less likely to intrude into the waking state, either in the form of waking fantasy, diffuse motor activity, or directed action. Thus, according to this model, comparison of the contents of daydreams with those of night dreams should show differences reflecting the relative use of the two states as channels for the reduction of tension.

Research supporting this model provides primarily circumstantial evidence (Singer and Rowe, 1962). The research which lends this circumstantial support usually compares fantasy productions to overt behavior, e.g., frequency of Rorschach M correlated with decreased motility and increased introspectiveness (Singer, 1955; Singer, 1960). An example of such a study in which the TAT was used is offered by Feshbach (1955). In this study, a group of students was insulted by an experimenter who 
then left the room. One-half of the students were asked to write TAT stories, while the other half engaged in a task which precluded fantasy. The hostility level of those allowed to engage in the TAT fantasy was significantly lower than the hostility level of those subjects who were assigned the fantasy-precluding task. This argues for the notion of fantasy as an alternative channel for the expression of hostile drives.

This study was replicated in some respects in a study conducted by Singer and Rowe (1962). In this study, students were surprised with a mid-term comprehensive examination which was not previously announced. Following the exam, half the students were asked to sit quietly for 10 minutes and meditate or daydream; the other half were asked to fill out an "absorbing attitude questionnaire." The findings were that anxiety increased over the 10-minute period for those subjects under the daydream instruction to a significantly greater degree than for the fantasy-precluded group. The researchers concluded that the drive reduction hypothesis with regard to fantasy as an alternative channel of expression may differentially apply to different drives or affects. Other studies have also come to similar conclusions. Kagan, for example, found that fighting themes in TAT stories were positively associated with aggressive overt behavior in a group of 118 grade-school boys (Kagan, 1956). Also, achievement striving of overt behavior has been predicted from achievement motive as scored in storytelling (Atkinson, 1958; McClelland, 1961).

In a study more closely related to the question of the relation of daydreaming to night dreaming, Cartwright compared REM and NREM reports of hospitalized schizophrenics to those of normals (Cartwright, 
1972). Since the schizophrenics were judged to engage in waking hallucinatory fantasy to a significantly greater degree than normals, it was hypothesized that DF ratings for REM would be significantly lower for the patient group than for the normals. This hypothes is was confirmed and Cartwright concluded that an inverse relationship exists between REM and waking fantasy in the degree of bizarreness expressed (DF).

Finally, qualified support for the alternative channels model is presented by a study which involved depriving subjects of REM sleep and measuring waking functions (Cartwright and Ratzel, 1972). In this study, 24 subjects were deprived of REM sleep and then tested on the WAIS and Rorschach. These test scores were compared with baseline scores obtained prior to the REM deprivation. For those subjects scoring low on the DF scale (REM mentation reports), significant changes in performance were observed. Specifically, an increase in Rorschach $M$ responses occurred, along with improved performance on the Picture Arrangement subtest of the WAIS. The authors concluded that these changes reflect an increase in the constructive use of fantasy which is "integrated with reality responses" (Cartwright and Ratzel, 1972, p. 280).

The relative value of the Cartwright and Ratzel study in support of alternative channels relies on the assumption that increases in Rorschach $M$ and Picture Arrangement scores correlate with increased tendency to engage in waking fantasy. The former does have some support in research, as noted in a previous section of this paper. Further, it should be noted that the second group of subjects, those rated high on DF scores from REM reports, did not show the changes in $M$ and WAIS 
performance. This suggests that the drive reduction hypothes is may apply to some subjects, but not to others. Since pre-deprivation Rorschach scores showed this latter group to be more responsive to internal stimuli (due to their higher $M$ response), the authors concluded that the differences observed in post-deprivation scores between the two groups indicated a state-specific tendency to engage in fantasy among the low REM DF subjects. This, again, suggests that the drive reduction, or alternative channels, hypothesis may be too simplistic, not allowing for differential patterns of fantasy use. 
CHAPTER $V$

\section{INDEPENDENT PROCESSES}

Gerald Vogel has recently elucidated a second view of the relation between daydreaming and night dreaming which derives from psychoanalytic theory (Vogel, 1978). He suggests that waking fantasy is a volitionally initiated state and that the degree of regression which occurs in this state is related to the lack of defensiveness. Lack of defensiveness is not equated with ego strength, but reflects the willingness of the individual to relax the rigid control exercised by the ego. Thus, waking fantasy is initiated by the ego's voluntary withdrawal of control over mentation. The person who experiences vivid and regressive waking fantasies is seen as a person who does not fear the loss of ego controls and therefore is able to volitionally initiate fantasy without exercising rigid defenses.

REM fantasy, on the other hand, is seen as non-volitionally initiated by the id and is thus expressive of unconscious needs and wishes. It is not related to volitionaliy initated fantasy, but is related to psychopathology which is seen as non-volitionally initiated waking mentation controlled by the id. This model suggests that there will be no correlation, positive or negative, between daydreaming and night dreaming, since the mechanisms which control the two states are different (ego vs. id). 
Vogel derives support for his hypothesis from studies comparing sleep onset mentation (SO) with REM mentation and waking fantasy (Foulkes and Rechtschaffen, 1974; Foulkes, Spear, and Symonds, 1966; Foulkes and Voge1, 1965; Voge1, Foulkes, and Trosman, 1966). In all of these studies, SO and REM reports were obtained using psychophysiological methods. These reports were compared to TAT stories as a measure of waking fantasy, and to personality variables as measured by the California Personality Inventory (Foulkes and Rechtschaffen, 1964; Foulkes et al., 1966). The results of these studies showed correlations between qualities of SO and waking fantsy which were not present between REM and SO or between REM and waking fantasy. These qualities included Dreamlike Fantasy (DF) and TAT imaginativeness, word count, and sexual content (Foulkes et al., 1966).

Further support for Vogel's theory is derived from the finding of correlations between SO DF and personality variables which did not hold for REM DF. Specifically, subjects having high DF scores during sleep onset were found to be more self-accepting, less rigidly conforming, and more socially poised than subjects scoring low on DF during sleep onset. The latter group scored high on characteristics associated with the authoritarian personality, i.e., rigid, conformist, and intolerant (Foulkes et al., 1966). Given that SO DF was positively correlated with personality variables associated with positive adjustment and with imaginativeness of waking fantasy, and since Vogel considers both SO and waking fantasy to be initiated voluntarily, he concludes that these two states are under the control of the ego. 
In contrast, Voge 1 cites a study in which REM DF was correlated with psychopathology (Foulkes and Rechtschaffen, 1964). In other words, the more bizarre and hallucinatory the mentation report obtained from REM, the more psychopathology exhibited by the subject. REM DF was uncorrelated with SO DF and TAT imaginativeness, but was related to psychopathology.

Basing his argument on the above findings, Vogel concludes that: (1) So fantasy can be classified as under the control of the ego because it is initiated voluntarily; (2) so and waking fantasy are related because both are initiated voluntarily; and (3) REM is non-volitionally initiated and is therefore not correlated with SO or waking fantasy, but is a correlate of psychopathology which is also seen as nonvolitionally controlled mentation under the control of the id. Vogel thus suggests that the id controls both REM and psychopathology, and that the ego controls SO and waking fantasy. Since the two states are under different controls, they represent independent processes.

Several criticisms can be made of this model. In a commentary to Vogel's 1978 article, John S. Antrobus (Antrobus, 1978) suggests that the relationship between waking fantasy, SO fantasy, and REM fantasy may not be a linear function, in which case, Pearson's $\underline{r}$ would not be reflective of the relationship.

It should also be pointed out that two measures were found to correlate between SO, REM, and TAT: aggression and hedonic tone (Foulkes et al., 1966). This indicates that Vogel's model may be simplistic; that although some qualities of the states are unrelated, others are. Although some controls may be unique to one or the other 
state, some mechanisms may indeed be shared. Further, it may be that TAT stories are not indicative of waking fantasy as measured by some other technique, e.g., the psychophysiological method. 


\section{CHAPTER VI}

CONTINUUM MODEL

In contrast to the ascendancy of drives of the Freudian model, and deriving impetus from evolutionary and biological theory, a third model has emerged. This model, eloquently described by Tomkins (1962) and Singer (1966), suggests that daydreaming and night dreaming vary on a continuum of attention (internal vs. external). Numerous variables have been postulated to influence variation on this continuum: complexity or variety of stimuli (Singer, 1966: Tomkins, 1962), enduring preferences for perceptual perspective (Singer, 1966; Witkin, Dyk, Patterson, Goodenough, and Karp, 1962), parental identification patterns (Singer, 1966), and numerous personality characteristics (Singer, 1966).

Man is seen as having innate needs for three classes of affect: preservation of life, social contact with other humans, and novelty of perceptual stimulation. That is, each individual will exert effort toward the attainment of positive affective states related to these classes. Some stimuli are seen as innate releasers of the experience of affects. For example, the infant smiles with joy in response to the mother, the person fears threats to his life (Tomkins, 1962).

Affects are seen as amplifiers of drive states; thus affects, not drives, motivate the person to engage in instrumental behavior aimed at the satisfaction of drives. For example, the person experiences displeasure (affect) when he is hungry, long before critical levels of 
tissue depletion are reached. This affect, displeasure, motivates the person to engage in a consummatory response. The person stops this behavior long before the tissue depletion is remedied, cued to discontinue the consummatory response by the affect of pleasure.

The affective motivational system is a biological given, however many of the specific stimuli which trigger affective states are learned. Additionally, many stimuli may elicit any given affect, and any given stimulus may elicit a variety of affects. These qualities of the affective motivational system, along with man's mobility in a changing environment, form the basis of Tomkins' notion of consciousness. A tree, for example, has no need of consciousness since the system is fixed, i.e., the receptors of the tree are programmed to respond in specific ways to specific stimuli, and there is no tolerance for ambiguity. Thus, a tree cannot survive a transplant from an arctic environment to the desert. Man, however, must have the capability to respond in ambiguous situations and Tomkins has postulated a mechanism which allows him to do so. This same mechanism is responsible for consciousness and altered states of consciousness, e.g., dreaming and hallucination. This mechanism has the capacity to duplicate and compare images of current stimuli, memories, and desired states.

Tomkins bases his notion of this central processing mechanism on the idea that the most fundamental characteristic of any living system is the process of duplication of information. The processes of the system under study, whether it be a species, an individual, or a subsystem of an individual, have as their final aim the duplication of information which is passed on to other systems or subsystems, which then 
duplicate the information for further systems, and so on. The human uses this information from his subsystems to achieve positive affective states, or the reduction of the intensity of negative affective states. This capacity in man has developed through the process of evolution, and has made possible man's ability to adapt and survive in a variety of environments. Other organisms have become extinct due to their inferior ability to match information with previous and desired states. These organisms lack the central processing mechanism suggested by Tomkins to be the basis of consciousness.

As mentioned earlier, satisfaction of drives is seen as subordinate to the affective system. An affective state cues instrumental behavior which seeks to satisfy a drive. It amplifies a drive and gains the attention of the organism. Affective states thus serve as the cues which the organism uses to maintain biological integrity. As the person develops from infancy, specific objects in the environment come to be associated with particular affective states. The survival of the person relies on his ability to form and retain images of these objects and the associated affective states. If the environment were unchanging, and the organism's position in that environment were unchanging, these associations would be fixed, as is the case with the tree. However, man is a particularly mobile creature in an environment that continually changes. It thus becomes necessary for man to possess some mechanism which can compare images of previous experiences with current perceptual cues, as well as with an image of the desired state.

Tomkins suggests that this process constitutes a feedback system which consists of afferent and efferent pathways which merge at a 
central processing station. This central mechanism translates afferent messages, through associations with previous experiences, into an image. The image may involve any of the senses and is presented with its affective associations. The afferent message is thus not directly perceived. What is perceived is an image constructed by a "central efferent process with attempts to duplicate the set of afferent messages" (Tomkins, 1962, p. 13). The person attempts to match the image of the afferent report with an image of the desired state. This matching is seen as a skill which is learned through practice with a changing environment. Thus, varied experience is needed for this cognitive skill to develop properly.

Singer (1966) suggests that the need for varied stimuli motivates the daydream response to monotonous stimuli. When this occurs, the person's attention is redirected from external to internal stimuli, along a continuum of variety. Since a person will also seek positive affective experience, Singer suggests that the person may be motivated to redirect his attention from an unpleasant external situation to a pleasant, internally stimulated daydream. Again, the person moves along a continuum of attention, from external to internal, and at the same time moves along a continuum of affect, from negative to positive.

As mentioned previously, image formation is a given ability which is differentiated by learning. If this is the case, then the flexibility to redirect attention should vary from person to person. Also, since the mechanism responsible for creating the images used in the processing of information from external stimuli is also responsible for processing internal stimuli, the style in which the person has learned to use this 
mechanism will be the same for daydreaming and night dreaming. Thus, in research which examines the two states, this model would hypothesize that the affect, content, and style of the two states will be similar.

If the skill to manipulate information is not well-developed, or if some organic defect exists, the person will not be able to store or retrieve images effectively. In some cases, there may be the inability to distinguish images as deriving from internal or external cues. This may be the case with schizophrenics. Negative or ruminative daydreams may represent repeated attempts to achieve positive affective states (or reduce negative affective states) by a person who has not fully developed his capacity to manipulate and compare images. As Tomkins suggests, the skill at image formation "eventually supports the dream and the hallucination" (Tomkins, 1963, p. 13).

Steven Starker has been prolific in his attempts to validate this mode1. In one study (Starker, 1974), he compared responses on the Imaginal Processes Inventory to dream diaries. He worked with 9 subjects, 3 from each of the daydreaming styles described earlier in this paper. He found that characteristics of the dream reports correlated with the daydreaming style of the subject. He coded the dream reports for bizarreness, emotionality (the extent to which emotion or affect is displayed in the dream), affective polarity (positive vs. negative), and length. The Positive-vivid daydreamers reported nocturnal dreams which were positively toned. These subjects also reported the least bizarreness. The Negative daydreamers reported night dreams which were more negatively toned and more bizarre. The Anxious-distractible daydreamers reported the most bizarre, most emotional, and most negatively toned 
dreams. He concluded that waking and sleeping fantasy can be considered to be similar with respect to the expression of affect and drive, and that they vary on a continuum of arousal.

The above results confirmed an earlier finding (Starker, 1973) of positive correlations between dream bizarreness and a scale of Bizarre and Improbable Daydreams (as measured by the IPI), as well as between negative affect in dreams and the frequency of Hostile Aggressive Daydreams and Fear of Failure in Daydreams (also as measured by the IPI). Again, the data on dreams were obtained through the use of a dream diary.

In a third study (Starker and Hasenfeld, 1976), again using the IPI and dream diary, the occurrence of nightmares and insomnia were found to be correlated with the Guilty-dysphoric daydream style and the Anxious-distractible style. In contrast, the Positive-vivid daydream style was uncorrelated with either measure of sleep disturbance.

A notable problem with all of these studies is that the measure of nocturnal dreaming is a conscious, written self-report, and as such might be expected to be similar to conscious, questionnaire responses to the IPI.

In a study which compared pre-sleep mentation reports with reports obtained from REM (psychophysiological method) it was found that content was "richly related" between the two states (Baekeland, Resch, and Katz, 1968). Subjects were asked to free associate for one-half hour after being prepared with electrode placements for EEG/EOG recordings. The cognitive style and content of these association periods were compared to the reports obtained from the subjects upon arousal from REM 
sleep. As mentioned, there was a high degree of congruence between the two states, especially in early REM periods of the night. This is consonant with a finding that the later in the night a REII report is obtained, the more temporally remote are the events related in the report (Verdone, 1965). These findings lend credence to the continuum model. Physiological arousal has also been shown to relate to sleep states in a continuum style. Hauri (1968) varied pre-sleep activity for subjects and measured the rate of decline of physiological arousal indicators (e.g., heart rate, pulse rate, body movements, respiratory rate, etc.). The activities were: (1) studying while physically relaxed, (2) strenuous physical exercise, and (3) relaxation (watching TV, reading magazines, etc.). He found that physiological arousal declined progressively in the first $3-1 / 2$ hours of sleep (he did not monitor further) and concludes that this supports the continuum theory. He suggests that the alternative channels theory implies that sleep is a complement to the waking state, and thus high physiological arousal in the waking state would be accompanied by low physiological arousal in sleep. His findings contradict the complementary (alternative channels) model. Hauri concludes that the continuum model is a more valid representation of the relation between waking and sleeping states. 
CHAPTER VII

\section{A DESCRIPTION OF THE PRESENT STUDY}

\section{STATEMENT OF PURPOSE}

The three models described in Chapters IV, V, and VI each enjoy a modicum of support from research. Each research effort cited in this paper has certain problems associated with it. However, a problem common to all the studies is the comparability of the various measures used to support the various hypotheses. With reference to dream research, does the report of a dream obtained from a subject aroused from a REM period resemble a dream reported in a dream diary? This issue is dealt with in an article cited earlier (Cartwright and Kaszniak, 1978). However, further evidence should be obtained from more direct comparisons of the two types of reporting situations than has been done to date. This is left for future research.

This project attempts to resolve certain issues bearing on the measurement of waking fantasy. One might ask what degree of similarity exists between a TAT story, a questionnaire, and an ongoing mentation report obtained from a physiologically monitored subject. An answer to this question could facilitate the attempt to resolve conflicting research findings.

The Foulkes and Fleisher study (1975), described earlier, was replicated. The findings of the present study are expressed in terms of percentages, as were the findings of the original study. 
Subjects were also asked to produce six TAT stories and to complete the Imaginal Processes Inventory. These three measures have been compared on seven dimensions (traits) to determine if they present a congruent picture of each subject's fantasy life. The method of statistical analysis for this aspect of the present study is a multitraitmultimethod correlation matrix, as described by Campbell and Fiske (1959). This matrix gives Pearson's $\underline{r}$ for each trait comparison: each trait by every other trait, as measured by the same method and by the other two methods. Although the matrix is rather unwieldy, it yields data which bear on two important issues: convergent validity (the degree of correlation between two measures of the same trait) and discriminant validity (the degree of correlation between one measure of a trait and other traits by the same method and by other methods). Campbell and Fiske point out that convergent validity is only the first step in establishing a more complete index of validity. Discriminant validity is also required in order to make a judgment about the validity of a particular method of trait measurement (1959). "High correlations between tests might be explained as due either to basic trait similarity or to shared method variance" (Campbell and Fiske, 1959, p. 84). The multitrait-multimethod matrix graphically illustrates patterns of significant correlations and thus presents data for convergent and discriminant validity.

Several other measures were completed by the subjects in connection with Study II, which proposes to examine the relationship of daydreaming to prevailing notions of image formation and right-left hemisphere activation and dominance. The measures employed for Study II 
were: the Betts Questionnaire of imagery vividness, the Gordon Test of imagery controllability, and a paired-associate learning task (PAL).

The following method section reports the procedures of all measures taken, in the order of administration. Those measures considered to be most susceptible to contamination by other aspects of the experiment were completed first. Statistical analysis is reported here only for the measures which relate to the purpose of Study I.

METHOD

Subjects

Twenty-five subjects were recruited from undergraduate psychology courses at Portland State University. A subject's participation was related to his grade in a course only to the extent that extra credit was offered by some instructors. Each subject was paid $\$ 5.00$ upon completion of all measures. Due to equipment failure and dropouts, the final $\underline{N}$ for this study was 16: 4 male and 12 female.

An initial interview was employed to screen for psychiatric disturbance, as well as to gather biographical data. Due to the recommendation for use of the Imaginal Processes Inventory, only native Englishspeaking subjects were used. Also, left-handedness was screened out, due to mixed hemisphere usage (Corballis and Beale, 1976).

The age range of the sample was 19 to 37 (mean $=25$, standard deviation $=5.28$ ). All subjects were Caucasian. Fifteen of the subjects were full-time summer students. One subject was not enrolled in classes for the summer, but was working as a research assistant in the Department of Psychology. Seven subjects stated an academic major in 
Psychology, two in Education, two in Business, two in General Studies (one in Social, one in Science), and one each in Nursing, Biology, and Social Work.

Eleven of the subjects stated an occupation. Five had part-time clerical/office jobs, one was an unemployed secretary/tutor, one a full-time machinist, two manual laborers (one employed part-time, one unemployed), one part-time musician/promoter, and one part-time salesperson. The remaining subjects did not report an occupation and were not working at the time of the study.

\section{Procedures}

The tasks were divided into two sessions, each of which took about two hours for the subject to complete. The first session was conducted with each individual separately; the second session was conducted with groups of subjects. The time of day that the sessions were scheduled was not randomly assigned. The critical factor in scheduling was simply the availability of the subject.

Session One. This session consisted of the OMR, the PAL, and the Betts and Gordon questionnaires.

For the OMR, the procedures used in this study approximated, as closely as possible based on the published article, those procedures employed by Foulkes and Fleisher (1975). The sessions were conducted at various times during the day between the hours of 9:00 A.M. and 8:00 P.M. Two OMRs occurred at 9:00 A.M., six at noon, six at 3:00 P.M., and two at 6:00 P.M.

The room was moderately illuminated by two table lamps (150 and 75 watts), each located approximately six feet from the subject. No 
attempt was made to eliminate incidental sounds from the hallway, although most subjects commented on the noise made by the ventilation system of the building. The noise was one of rushing air, and resembled white noise. Every attempt was made to provide a setting which was similar to one encountered in everyday situations of relaxation.

Subjects were oriented to the task as a daytime practice session for the establishment of waking baseline responses to a structured interview designed for use in sleep research. The nature of sleep research was described to the subject (i.e., monitoring of sleep, awakenings, and use of the interview questions). It was pointed out to the subject that the questions may not apply too well to waking experiences. See Appendix A for the script used for this orientation.

Electrode placements for EEG and EOG monitoring were then made. Frontal placements were used for the EEG, and EOG placements were made according to the criteria outline in Rechtschaffen and Kales (1968). The subject was shown a copy of the questionnaire to be used in reporting mentation. See Appendix B for a list of these questions. The experimenter reviewed each question with the subject to ensure understanding. During this time, a second experimenter calibrated the physiograph in the next room.

The subject was then asked to lie down and relax but stay awake. It was suggested that the subject might want to close his eyes to promote relaxation, but that this was not a requirement. The experimenter then left the room and allowed a five-minute adaptation period before beginning the timed interruptions. Subjects remained in this relaxed state for 45 to 60 minutes during which time the experimenter, isolated 
in the next room, interrupted the subject at six randomiy selected times. The interruptions ranged from one to nine minutes after the end of the previous interview (introductory interview/adaptation period or mentation report). The experimenter called the subject's name over a speaker system, and went through the questions contained in Appendix B.

The subject's answers were recorded on magnetic tape, transcribed on individual scoring sheets, randomly ordered, and given to two judges to rate for the content areas under study.

In order to make comparisons with previous research, OMR responses were scored for regressivity and reality contact. In order to make comparisons with other measures used in this study, the reports were rated for emotional tone $(E T)$, outcome $(0)$, achievement $(\tilde{A C H})$, aggression $(A G)$, sex $(S X)$, bizarreness (BZ), and vividness (VV). The coding systems used are described in more detail later in this paper, and the specific criteria for each system are included in Appendices $C$ through I.

A four-channel physiograph (E \& M Instruments, Model 4-A) was used to monitor EEG and EOG for the entire relaxation period. The paper speed was $1.0 \mathrm{~cm} / \mathrm{sec}$, the minimum speed recommended by Rechtschaffen and Kales (1968) for reliable recording of EOG and EEG. Selective filtering was set at $30 \mathrm{~Hz}$, except during periods of interference (60-cycle fluctuations, subject muscle tension, etc.), at which times the filter was set at $10 \mathrm{~Hz}$. Pen deflection ranged from $20 \mathrm{0mV} / \mathrm{cm}$ when the filter was set on $30 \mathrm{~Hz}$, to $50 \mathrm{0mV} / \mathrm{cm}$ when the filter was set at $10 \mathrm{~Hz}$.

The physiograph record was used to determine lateral eye movements to be used in Study II. This record also provided a basis for judging 
whether or not the subject was awake or asleep at the time of the mentation report. Slow, rolling eye movement was the primary indicator of sleep onset. Additionally, a report from the subject that he was "drowsy," "drifting off," or in "light sleep" (Question 10) was used as a criterion. When both the physiological and subjective assessment coincided in indicating sleep onset, the report obtained was discarded. Thus, the interruptions scored and reported here were obtained from waking subjects.

The paired-associate learning task (PAL) used a revision of the procedure used by Yuille and Paivio (1968). All subjects were instructed that the experiment was concerned with the learning of nounpairs. Each noun-pair was presented manually by the experimenter at a constant rate of 6 seconds per card. Each subject participated in four separate paired-associate learning trials, each trial consisting of a list of 10 noun-pairs. During this time, the subject was continuously monitored by EEG and EOG recordings.

The conditions for trial I excluded prior mnemonic instructions and were identical for all subjects. Following the general procedural instructions, each subject was presented the first list of noun-pairs. The list consisted of five concrete and five abstract noun-pairs presented in random order. This was followed by a recall test, with the experimenter presenting the stimulus noun for six seconds, and the subject recalling and writing the response noun. The subject then filled out a brief questionnaire describing how he remembered the noun-pairs. Trial I yielded a baseline measure of PAL performance for all subjects. 
The conditions for trials II and III included two different mnemonic instructions (imagery and verbal) and two corresponding PA lists (concrete and abstract, respectively). The order of sequence for trials II and III were counterbalanced so that half the subjects were randomity selected to receive trial II first and trial III second. The remaining half of the subjects received trial III first and trial II second.

For trial II, each subject was told that he would learn a mnemonic technique which would help him to remember word lists. The subject was then told how to combine each noun-pair by forming a mental image, or picture, of the appropriate object. Each subject then practiced the technique with two noun-pairs, drawing the image on paper so that the subject's understanding of the imagery instructions could be verified. It was emphasized that the quality of the drawing was unimportant. The subject was then presented with a list of ten concrete noun-pairs, followed by a recall test, as in trial I. This was followed by a questionnaire.

The procedure for trial III was the same as for trial II, except that an abstract word list was employed and the subjects were instructed to use a verbal mnemonic strategy. Each subject was instructed to construct a sentence or phrase for each noun-pair in which the nouns were embedded and associated in some manner. On the two practice nounpairs, the subject was asked to write down the mediating phrase, again to insure the subject's understanding of the technique. The questionnaire followed the recall test, as in trials I and II. 
The conditions of trial IV repeated those of trial I. The subject received no mnemonic instruction and was told to perform the task in the easiest manner. The PA list, as in trial I, consisted of five concrete and five abstract noun-pairs presented in random order, followed by a recall test and questionnaire.

The nouns in the four paired-associate lists (10 pairs each) were selected from a list of 925 nouns with norms for concreteness (C), imagery (I), and meaningfulness (Paivio, Yuille, and Madrigan, 1968). The concrete list consisted of 20 randomly paired nouns rated high on $\mathrm{C}$ and I (means approximately matched across words). The abstract list consisted of 20 randomly paired nouns rated low on C and I. The frequency of usage for all nouns was approximately matched across all words (Thorndike and Lorge, 1944). Each word pair was typed in upper case letters on an unlined $3^{\prime \prime} \times 5^{\prime \prime}$ card.

The self-report, post-trial questionnaire consisted of two parts. The first part contained two questions with corresponding 7-point scales. The scale for Question 1 (how easy or difficult the subject found the instructed mnemonic strategy) was defined by 1 (very easy) to 7 (very difficult). The scale for Question 2 (how often the subject used the instructed technique) was defined by 1 (none of the pairs) to 7 (a11 of the pairs). The second part of the questionnaire contained a list of the noun-pairs employed in the preceding trial, along with instructions for the subject to draw (trial II) or write (trial III) the mnemonic mediation actually used to remember each noun-pair.

The Betts and Gordon Questionnaires were given at the end of the PAL. The Betts is a subjective measure of vividness of imagery. 
Sheehan's shortened version of the Betts was used, as it appears in Richardson (1969). It contains seven subscales which require the subject to rate the clarity and vividness of specific images across the different sense modalities: visual, auditory, tactile, kinesthetic, taste, sme 11, and bodily sensations. All subtests use a rating scale from 1 to 7 , with a rating of 1 representing images which are "perfectly clear and as vivid as the actual experience" and a rating of 7 representing "no image present at all, you only know that you are thinking of the object."

The Gordon test of imagery controllability, as revised by Richardson (1972), followed the Betts Questionnaire. The subject was instructed to visualize a specific image in each of the sense modalities listed above, and was then asked to change the image in a specific way. The subject was then asked to rate his ability to visualize the requested scene by indicating yes or no. The instructions emphasize the ability to control and change imagery rather than the vividness of the imagery. The Gordon Test and Betts Questionnaire were administered on an individual basis as advised by Richardson (1972).

Session Two. This session consisted of group administration of the Thematic Apperception Test and the Imaginal Processes Inventory, as well as payment of subjects.

The subjects were asked to respond to six TAT cards (4,7BM, 10, 13MF, 14 and 20) in a session conducted by the experimenter. The cards were selected to yield a variety of themes, according to the normative data reported by Eron (1950). The cards were also selected as 
moderately ambiguous, according to the list provided by Bijou and Kenney (1951).

The cards were projected on a screen with an overhead projector, each card being projected for one minute. The subjects were given five minutes to write their responses. The stories thus obtained were coded by two independent judges for the same categories, using the same criteria as the OMR. Regressivity and reality contact were not scored for TAT stories. The latter two measures were scored only for the purpose of comparing the results of this study with the findings of Foulkes and Fleisher (1975).

When instructing the subjects, the experimenter made no reference to the purpose of the test. The subjects were asked to write three aspects of the story: (1) what is going on in the scene? (2) what led up to the scene? and (3) what will the outcome be?

Upon completion of the TAT, each subject was asked to complete the IPI. The administration of this test was done as a group, after which the experimenters explained the purposes of the study, answered questions, and paid the subjects. A list of the 28 scales of the IPI is located in Appendix $\mathrm{J}$.

\section{Scoring Systems}

As stated previously, each report/story was transcribed on an individual scoring sheet. The sheets were then randomly sorted, and each of two judges received a copy of all reports/stories.

The OMR reports were coded for regressivity and reality contact, as previously described. The specific criteria for these two categories 
are located in Appendices $C$ and D. OMR and TAT were both scored for the following categories.

Emotional tone (ET) and Outcome (0) were coded according to the criteria outlined by Eron (1950). In both categories, ratings were made ranging from -2 (very sad, very negative outcome) to t2 (very happy, very positive outcome). A rating of 0 indicated neutral emotional tone, the continuation of circumstances, or a balance of positive and negative affects/outcomes. Murstein reports inter-judge reliability to be in the middle $80 \mathrm{~s}$ in most uses of the system.(Murstein, 1973). See Appendices $E$ and $F$ for specific criteria.

Achievement $(\mathrm{ACH})$ was scored according to a revision of the criteria set forth by McClelland et al. (1976). McClelland's system begins with a judgment of whether or not the report contains any imagery related to achievement. This judgment yields a score of -1 for Unrelated Imagery (UI), 0 for Doubtful Imagery (TI), and +1 for Achievement Imagery ( $A I)$. If a report receives $a+1$, it is then scored for the following categories: Stated need for achievement (N), Instrumental activity with positive/neutral/negative outcome (I+, I?, I-), Anticipatory Goal States (Ga+, Ga-), Obstacles or blocks (Bp, Bw), Nurturant Press (NuP), Affective States (G+, G-), and Achievement Thema (AchTh). Each quality is scored by adding one point if it is present in the story. This system yields a range of values from -1 to +11 . Since the full Achievement scale includes outcome expectations, affects, and other qualities which are coded by other scales in this study, and since it seems multidimensional (in terms of what it is about the report that is being measured), this study scored Achievement by a modified 
scale. This modified scale was based on four of McClelland's criteria: AI, N, I, and AchTh. Murstein reports that inter-judge reliability on the full scale is high in studies which use expert judges, yielding values in the low 90s (Murstein, 1963). Detailed descriptions of the criteria for the modified scale are located in Appendix G.

Aggression (AG) and sex $(S X)$ were rated on a scale designed by this author which parallels the McClelland system described above. First the presence or absence of related imagery was rated. If the report scores +1 on this criterion, the report will then be rated for $N$ (direct expression of theme by any character mentioned in the report), I (instrumental activity involving the theme), and AggTh or SexTh (theme is central to report, not incidental). Specific scoring criteria are located in Appendix G.

Bizarreness (BZ) of the events reported were scored by assigning numerical values to modified criteria of regressivity as reported by Vogel et al. (Vogel, Foulkes, and Trosman, 1966). Modification consisted of removing from the criteria any mention of hallucinatory quality of the report. The reports were thus rated from 0 (single, isolated image of improbable nature, e.g., a brick suspended in mid-air), to 3 (magical, omnipotent, or extremely unusual events reported in a sequence, e.g., a brick soaring through water while the subject dissolves into thin air to avoid being hit by the brick). Specific criteria are located in Appendix H.

Vividness (VV) of imagery was assessed by a modification of the Dreamlike Fantasy scale (Foulkes, 1971; Foulkes, Spear, and Symonds, 1966). This scale consists of rating the report from 0 (no content 
reported, feels mind was blank) to 7 (perceptual content which is hallucinatory). The modified scale, which removes any mention of the bizarreness of the image, ranges in value from 0 to 3 , using the same end-points as the full scale. The modified scale is presented in Appendix I. 
CHAPTER VIII

\section{RESULTS}

\section{REPLICATION OF THE FOULKES AND FLEISHER STUDY}

Of 96 arousals, 88 yielded waking content reports. Each report was rated by two independent judges for regressivity and reality contact. Tables I and II summarize the reliability of the two judges' ratings in terms of $\mathrm{chi}^{2}$ and phi coefficient. For regressivity, $\mathrm{chi}^{2}=$ $46.29(\mathrm{df}=1, p<.001)$ and $\mathrm{phi}=.725$. For reality contact, a judgment of "yes" means that some degree of reality contact was lost at the time of the report and that the judges agree on which aspects were lost. Again, chi ${ }^{2}$ was significant at the .001 level $\left(c h i^{2}=76.14, \mathrm{df}=1\right.$, phi $=.930)$. These values, for both ego functions, indicate that the ratings were very reliable between judges, and that little of the variability in scores can be attributed to variable ratings by the judges. It should be noted that $c h i^{2}$ is somewhat overestimated by values in any quadrant which are under 10; however, the values of $\mathrm{chi}^{2}$ obtained in this analysis are well beyond the cut-off value of $\mathrm{chi}^{2}$ corresponding to .001 significance $\left(\mathrm{chi}^{2}\right.$ at $\left..001=10.8, \mathrm{df}=1\right)$. Even so, the possibility of a spurious result should be kept in mind.

The results of this study are substantially congruent with the findings of the original study (Foulkes and Fleisher, 1975). Of the 88 usable reports, $57(65 \%)$ contained endogenous imagery (subject reported seeing something that was not there). This compares to the original 
TABLE I

RELIABILITY OF JUDGES' RATINGS OF REGRESSIVITY

\begin{tabular}{cc|c|c|c}
\hline \multicolumn{1}{c}{} & \multicolumn{3}{c}{ Judge 1 } \\
\cline { 2 - 5 } Judge 2 & Yes & No & \\
\cline { 2 - 5 } & Yes & 9 & 5 & 14 \\
\hline No & 1 & 73 & 74 \\
\hline & & 10 & 78 & 88 \\
\hline
\end{tabular}

$\mathrm{Chi}^{2}=46.29, \mathrm{df}=1$

$\mathrm{p}<.001$

phi $=.725$

TABLE II

RELIABILITY OF JUDGES' RATINGS OF REALITY CONTACT

\begin{tabular}{cc|c|c|c}
\hline \multirow{2}{*}{} & \multicolumn{3}{c}{ Judge 1 } \\
\cline { 2 - 4 } & \multirow{3}{*}{ Judge 2 } & Yes & No & \\
\cline { 2 - 5 } & Yes & 53 & 3 & 56 \\
\hline No & 0 & 32 & 32 \\
\hline & & 53 & 35 & 88 \\
\hline
\end{tabular}

$\mathrm{Chi}^{2}=76.14, \mathrm{df}=1$

$\mathrm{p}<.001$

phi $=.930$

finding that $68 \%$ of the reports contained endogenous imagery. All of the 16 subjects in the present study reported endogenous imagery (vs. 18 of 20 subjects in the original study).

of the 57 endogenous reports obtained, $40 \%$ were hallucinatory (subject could not distinguish between an internal and an external event). This compares to the original finding that $27 \%$ of endogenous reports were hallucinatory. Twelve of the present subject sample reported hallucination, whereas 11 of the original study's sample reported 
hallucination ( $75 \%$ vs. $55 \%$ ). Considering all usable reports $(\underline{N}=88)$, the percentage of hallucinatory reports was $26 \%$. The original study found $19 \%$ of all reports to be hallucinatory. These data are summarized in Table III.

\section{TABLE II I}

COMPARISON OF THE PRESENT RESULTS WITH THOSE OF FOULKES AND FLEISHER: HALLUCINATORY AND ENDOGENOUS IMAGERY

\begin{tabular}{|c|c|c|}
\hline Description & Present Study & Foulkes and Fleisher \\
\hline Endogenous imagery & $\begin{array}{l}65 \% \text { of al1 reports } \\
(\underline{N}=88)\end{array}$ & $\begin{array}{l}65 \% \text { of al1 reports } \\
(\underline{N}=115)\end{array}$ \\
\hline $\begin{array}{l}\text { Subjects reporting } \\
\text { endogenous imagery }\end{array}$ & $\begin{array}{c}100 \% \\
(\underline{N}=16)\end{array}$ & $\begin{array}{c}90 \% \\
(\underline{N}=20)\end{array}$ \\
\hline $\begin{array}{l}\text { Endogenous reports which } \\
\text { were also hallucinatory }\end{array}$ & $\begin{array}{c}40 \% \\
(\underline{N}=57)\end{array}$ & $\begin{array}{l}27 \% \\
(\underline{N}=78)\end{array}$ \\
\hline $\begin{array}{l}\text { Subjects reporting hallu- } \\
\text { cinatory imagery }\end{array}$ & $\begin{array}{c}75 \% \\
(\underline{N}=16)\end{array}$ & $\begin{array}{l}55 \% \\
(\underline{N}=20)\end{array}$ \\
\hline Hallucinatory imagery & $\begin{array}{l}26 \% \text { of al1 reports } \\
(\underline{N}=88)\end{array}$ & $\begin{array}{l}20 \% \\
(\underline{N}=115)\end{array}$ \\
\hline
\end{tabular}

Foulkes and Fleisher defined four major patterns of reality contact:

(1) Full contact--subject is controlling his thoughts (Q. 8), is aware that he is in the $1 a b(Q .7)$, and his mentation is not hallucinatory (Q. 6).

Of the 88 reports, $33(38 \%)$ fall into this pattern. Foulkes and Fleisher reported $38 \%$.

(2) Mind wandering--subject is not controlling his thoughts, but is aware he is in the lab, and his mentation is not hallucinatory. 
This study found $15(17 \%)$ in this category. Foulkes and Fleisher found $20 \%$.

(3) Lost in thought--subject may or may not be controlling his thoughts, he is NOT aware he is in the lab, and his mentation is NOT hallucinatory.

This report found $9(10 \%)$ of the 88 reports to fall into this category. Foulkes and Fleisher found $22 \%$.

(4) Complete loss of reality contact--subject is NOT controlling his thoughts, is NOT aware he is in the lab, and his mentation IS hallucinatory.

This study found $16(18 \%)$ of the 88 reports to lack reality contact altogether, which compares to Foulkes and Fleisher's finding of $15 \%$.

The above data are summarized in Table IV.

\section{TABLE IV}

COMPARISON OF THE PRESENT RESULTS WITH THOSE OF FOULKES AND FLEISHER: PATTERNS OF REALITY CONTACT

\begin{tabular}{l|c|c|}
\hline $\begin{array}{c}\text { Pattern of } \\
\text { Reality Contact }\end{array}$ & $\begin{array}{c}\text { Present Study } \\
(\underline{\mathbf{N}}=88)\end{array}$ & $\begin{array}{c}\text { Foulkes and Fleisher } \\
(\underline{\mathbf{N}}=118)\end{array}$ \\
\hline Full contact & $38 \%$ & $38 \%$ \\
Mind wandering & $17 \%$ & $20 \%$ \\
Lost in thought & $10 \%$ & $22 \%$ \\
Complete loss & $18 \%$ & $15 \%$ \\
Aberrant patterns & $17 \%$ & $5 \%$ \\
\hline
\end{tabular}

Of the 88 reports, $15(17 \%)$ were judged to be regressive. The original study reports $25 \%$ regressive. Of the 15 regressive reports in the present study, $20 \%$ occurred in the full-contact pattern of reality contact (vs. $20 \%$ in the original study), $7 \%$ in the mind-wandering 
pattern (not given in the original study), $27 \%$ in the lost-in-thought pattern (vs. $37 \%$ ), and $20 \%$ in the complete-loss pattern (not given in the original study). The data described above are summarized in Table V.

\section{TABLE V}

COMPARISON OF THE PRESENT RESULTS WITH THOSE OF FOULKES AND FLEISHER: REGRESSIVITY AND PATTERNS OF REALITY CONTACT

\begin{tabular}{|c|c|c|}
\hline Description & $\begin{array}{l}\text { Present Study } \\
\qquad \underline{N}=88)\end{array}$ & $\begin{array}{c}\text { Foulkes and Fleisher } \\
(\underline{N}=118)\end{array}$ \\
\hline Regressive & $17 \%$ & $25 \%$ \\
\hline $\begin{array}{l}\text { Regressive with full } \\
\text { contact }\end{array}$ & $\begin{array}{l}20 \% \text { of all regressive } \\
\text { reports }(\underline{N}=15)\end{array}$ & $\begin{array}{l}20 \% \text { of a]l regressive } \\
\text { reports ( } \mathbb{N} \text { not given) }\end{array}$ \\
\hline $\begin{array}{l}\text { Regressive with mind } \\
\text { wandering }\end{array}$ & $\begin{array}{l}7 \% \text { of all regressive } \\
\text { reports }\end{array}$ & Not given \\
\hline $\begin{array}{l}\text { Regressive with lost- } \\
\text { in-thought }\end{array}$ & $\begin{array}{l}27 \% \text { of all regressive } \\
\text { reports }\end{array}$ & $\begin{array}{l}37 \% \text { of all regressive } \\
\text { reports }\end{array}$ \\
\hline $\begin{array}{l}\text { Regressive with com- } \\
\text { plete loss }\end{array}$ & $\begin{array}{l}20 \% \text { of all regressive } \\
\text { reports }\end{array}$ & Not given \\
\hline
\end{tabular}

Foulkes and Fleisher noted a tendency for regressivity and hallucination to occur in a systematic relationship to one another (1975, p. 69). Of their 118 reports, $61 \%$ were not regressive and not hallucinatory, $19 \%$ were regressive but not hallucinatory, and $14 \%$ were hallucinatory but not regressive. Only $6 \%$ were both regressive and hallucinatory. They conclude that hallucination and regressivity were "relatively independent report characteristics" (Foulkes and Fleisher, 1975, p. 69). The present data, in the form of $c h i^{2}$ analysis, do not support that statement. $C h i^{2}$ for the present results equalled $2.77(\mathrm{df}=1)$, which is not significant at the usual criterion $(p<.05)$. Table VI illustrates these data. 
TABLE VI

$\mathrm{CHI}^{2}$ ANALYSIS OF THE INCIDENCE OF REGRESSIVE AND HALLUCINATORY MENTATION

\begin{tabular}{|l|c|c|c|}
\hline \hline & Not Hallucinatory & Hallucinatory & \\
\hline Not Regressive & $\begin{array}{c}57 \\
(64.8 \%)\end{array}$ & $\begin{array}{c}16 \\
(18.2 \%)\end{array}$ & $\begin{array}{c}73 \\
(83.0 \%)\end{array}$ \\
\hline Regressive & $\begin{array}{c}8 \\
(9.0 \%)\end{array}$ & $\begin{array}{c}7 \\
(8.0 \%)\end{array}$ & $\begin{array}{c}15 \\
(17.0 \%)\end{array}$ \\
\hline & $\begin{array}{c}65 \\
(73.9 \%)\end{array}$ & $(26.1 \%)$ & $\begin{array}{c}88 \\
(100.0 \%)\end{array}$ \\
\hline
\end{tabular}

Corrected $\mathrm{chi}^{2}=2.77, \mathrm{df}=1$

$\mathrm{p}<.0960$

phi $=.212$

\section{COMPARISON OF THE THREE DIFFERENT MEASURES}

The results of testing, as mentioned previously, were analyzed by constructing a correlation matrix which lists Pearson's $\underline{r}$ for each variable tested (ET, $0, A C H, A G, S X, B Z, V V)$, by every other variable, as measured by the same method, and as measured by the other two methods. Table VII presents the multitrait-multimethod matrix for the seven traits (variables) under study, as measured by the three different techniques.

Due to the subjective nature of some of the trait judgments, an average of the two judges' ratings for each quality, for each report/ story, was used in calculating Pearson's $\underline{r}$ for the multitraitmultimethod matrix (Table VII). Each subject's scores on each quality were averaged over all reports/stories, yielding an average score for each quality for OMR and for TAT. Thus, each subject had seven scores 


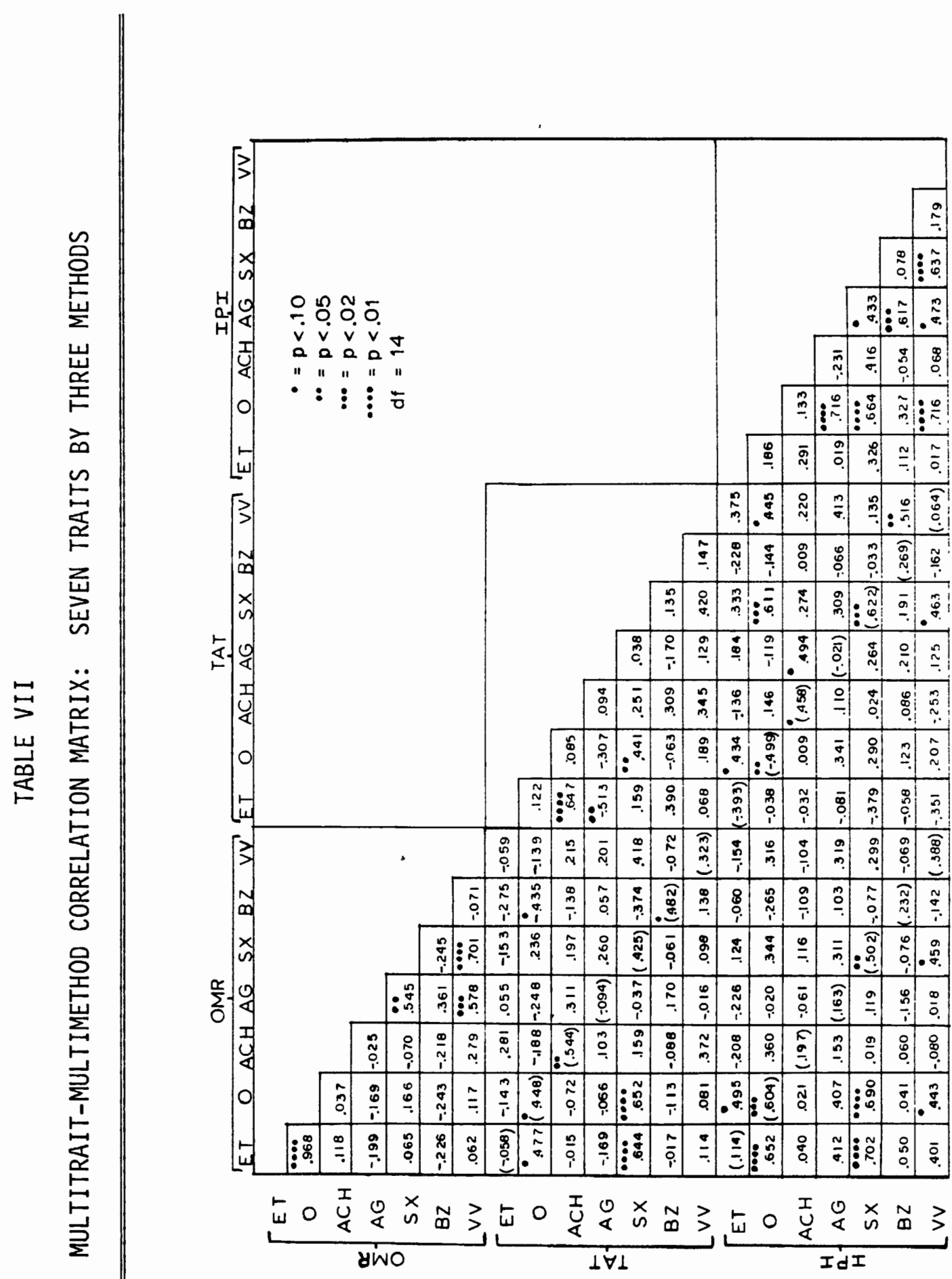


for OMR, seven scores for TAT, and seven scores for IPI. Table VII reports the correlations based on sixteen sets of scores.

Table VIII summarizes the significant correlations found in the validity diagonals, the heterotrait-monomethod triangles, and the heterotrait-heteromethod triangles. All correlation coefficients are expressed in terms of Pearson's $\underline{r}$, and significance levels are noted from .10 to .01 alpha.

TABLE VIII

SUMMARY LIST OF SIGNIFICANT CORRELATIONS

\begin{tabular}{l|l|l}
\hline Location & Variable(s) & Pearson's $\underline{r}$ \\
\hline \multicolumn{3}{c}{ Validity Diagonals } \\
\hline OMR x TAT & Outcome & $.448^{\star}$ \\
OMR X IPI & Achievement & $.544^{\star \star}$ \\
& Outcome & $.604^{\star \star *}$ \\
TAT X IPI & Sex & $.502^{\star \star}$ \\
& Outcome & $-.499^{\star *}$ \\
& Achievement & $.458^{\star}$ \\
& Sex & $.622^{\star \star *}$ \\
\hline
\end{tabular}

Heterotrait-Monomethod Triangles

\begin{tabular}{|c|c|c|}
\hline OMR & $\begin{array}{lll}E T & \times 0 \\
S X & \times & A G \\
V V & \times A G\end{array}$ & $\begin{array}{l}.968^{\star \star \star \star \star} \\
.545^{\star \star} \\
.578^{\star \star \star}\end{array}$ \\
\hline TAT & $\begin{array}{l}E T \times A C H \\
E T \times A G \\
S X \times 0\end{array}$ & $\begin{array}{c}.647^{\star \star \star \star} \\
-.513^{\star \star} \\
.447^{\star \star}\end{array}$ \\
\hline IPI & $\begin{array}{l}A G \times 0 \\
S X \times 0 \\
S X \times A G \\
B Z \times A G \\
V V \times \\
V V \times \\
V V \times A G \\
V V \times S X\end{array}$ & $\begin{array}{l}.716^{\star \star \star \star} \\
.664^{\star \star \star \star} \\
.433^{\star} \\
.617^{\star \star \star} \\
.716^{\star \star \star \star} \\
.473^{\star} \\
.637^{\star \star \star \star}\end{array}$ \\
\hline
\end{tabular}


TABLE VIII--Continued

\begin{tabular}{|c|c|c|}
\hline Location & $\operatorname{Variable}(s)$ & Pearson's $\underline{r}$ \\
\hline \multicolumn{3}{|c|}{ Heterotrait-Heteromethod Triangles } \\
\hline OMR $\times$ TAT & $\begin{array}{lll}E T & \times & 0 \\
E T & \times & S X \\
0 & x & S X \\
B Z & \times & 0\end{array}$ & $\begin{array}{l}.477^{\star} \\
.644^{\star \star \star \star \star} \\
.652^{\star \star \star \star \star} \\
-.435^{\star}\end{array}$ \\
\hline OMR $\times$ IPI & $\begin{array}{lll}E T & \times & 0 \\
E T & \times & S X \\
0 & \times & E T \\
0 & \times & S X \\
0 & \times & V V \\
S X & \times & V V\end{array}$ & $\begin{array}{l}.652^{\star \star \star \star \star} \\
.702^{\star \star \star \star} \\
.495^{\star} \\
.690^{\star \star \star \star \star} \\
.443^{\star} \\
.459^{\star}\end{array}$ \\
\hline TAT $\times$ IPI & $\begin{array}{lll}0 & \times & E T \\
A G & \times & A C H \\
S X & \times & 0 \\
S X & \times & V V \\
V V & \times & 0 \\
V V & \times & B Z\end{array}$ & $\begin{array}{l}.434^{\star} \\
.494^{\star} \\
.611^{\star \star \star} \\
.463^{\star} \\
.445^{\star} \\
.516^{\star \star}\end{array}$ \\
\hline
\end{tabular}

$$
\begin{aligned}
d f & =14, \text { two-tailed tests } \\
\star & =p<.10 \\
\star \star & =p<.05 \\
\star * \star & =p<.02 \\
\star * \star * & =p<.01
\end{aligned}
$$

Table IX reports the reliability of the two judges' ratings for each quality on the OMR and TAT in terms of Pearson's $\underline{r}$. All of these correlations, except one, were significant at the .001 level $(d f=86)$. Bizarreness on the OMR did not gain significance $(p<.101)$ which reflects subjective differences between the two judges. That is, what was bizarre to one judge was not bizarre to the other. This is the type of difference which led to the decision to use an average of the two judges' ratings in calculating Pearson's $\underline{r}$ for Table VII. 
TABLE IX

RELIABILITY OF JUDGES' RATINGS FOR EACH TRAIT IN TERMS OF PEARSON'S $r$ : OMR AND TAT

\begin{tabular}{c|c|c|c|c|c|c|c|}
\hline & $E T$ & 0 & $A C H$ & $A G$ & $S X$ & $B Z$ & $V V$ \\
\hline OMR & .812 & .679 & .532 & .743 & .929 & $.138^{\star}$ & .914 \\
\hline TAT & .656 & .711 & .732 & .868 & .530 & .755 & .413 \\
\hline
\end{tabular}

All values significant at .001 unless otherwise noted $(d f=86)$. $\star_{p}<.101$

Table $X$ reports the mean and standard deviation of each trait as measured by the OMR, TAT, and IPI. The range of possible scores for each quality should be kept in mind when reading Table $X$. For example,

$$
\text { OMR-ET- } \bar{X}=-.0354
$$

means that the average Emotional Tone of OMRs was slightiy negative, since the range of possible scores is: -2 (very negative) to +2 (very positive), with a rating of 0 indicating a neutral tone. Outcome can be interpreted in a similar way, since the range and definition of possible scores is the same as for Emotional Tone.

With regard to the content categories $(A C H, A G$, and $S X$ ) the range is -1 to +4 ; a rating of -1 indicates that the content area was not present, and a rating of +4 indicates that it was strongly present. The range for Bizarreness (BZ) and Vividness (VV) is 0 to 3 and those scores can be interpreted in a simple ordinal way. The reader is referred to Appendices $E$ through I for specific rating criteria and meaning of a particular mean value. IPI scores for all scales had a possible range of 12 to 60 . 
TABLE $X$

MEAN AND STANDARD DEVIATION FOR EACH TRAIT: OMR, TAT, AND IPI

\begin{tabular}{|c|c|c|c|c|c|c|c|}
\hline & ET & 0 & $\mathrm{ACH}$ & $A G$ & SX & $B Z$ & VV \\
\hline $\begin{array}{r}\text { OMR }-\bar{X} \\
\text { SD }\end{array}$ & $\begin{array}{r}-.0354 \\
.3429\end{array}$ & $\begin{array}{r}-.0001 \\
.3291\end{array}$ & $\begin{array}{r}-.8010 \\
.2317\end{array}$ & $\begin{array}{r}-.9062 \\
.1578\end{array}$ & $\begin{array}{r}-.8750 \\
.2966\end{array}$ & $\begin{array}{l}.0676 \\
.0924\end{array}$ & $\begin{array}{r}1.8519 \\
.4879\end{array}$ \\
\hline $\begin{array}{r}\text { TAT }-\bar{X} \\
\text { SD }\end{array}$ & $\begin{array}{r}-.4324 \\
.3934\end{array}$ & $\begin{array}{r}-.0470 \\
.3414\end{array}$ & $\begin{array}{r}-.4999 \\
.6512\end{array}$ & $\begin{array}{r}-.3438 \\
.4914\end{array}$ & $\begin{array}{r}-.7240 \\
.3622\end{array}$ & $\begin{array}{l}.1823 \\
.2858\end{array}$ & $\begin{array}{r}2.4167 \\
.3651\end{array}$ \\
\hline $\begin{array}{r}I P I-\bar{X} \\
S D\end{array}$ & $\begin{array}{r}42.3800 \\
6.8200\end{array}$ & $\begin{array}{r}21.3800 \\
8.1300\end{array}$ & $\begin{array}{r}37.0600 \\
8.6500\end{array}$ & $\begin{array}{l}25.3800 \\
11.0900\end{array}$ & $\begin{array}{l}38.5000 \\
12.1300\end{array}$ & $\begin{array}{r}28.2500 \\
6.6600\end{array}$ & $\begin{array}{r}21.5600 \\
7.7800\end{array}$ \\
\hline
\end{tabular}

Table XI presents the means and standard deviations on the IPI scales used in this study, along with means and standard deviations based on a normative study of the IPI which has not yet been released in published form (Segal, Huba, and Singer, 1980). These data are presented only for comparison with the results of this thesis and may not be reproduced for any other purpose without the express consent of the authors. Dr. George Huba related these data in a personal communication (Huba, 1980).

Since the data in the normative sample were broken down by sex, the data of the present study were also broken down by sex in order to make sensible comparisons. However, due to the small $\underline{\mathrm{N}}$ of the present study, t-test comparisons were not made. A discussion of how these data compare is reserved for the discussion section of this paper. 


\section{TABLE XI}

IPI MEANS AND STANDARD DEVIATIONS: COMPARISON OF PRESENT RESULTS WITH NORMATIVE DATA*

\begin{tabular}{|c|c|c|c|c|c|c|}
\hline \multirow[b]{2}{*}{ Labe 1} & \multirow{2}{*}{$\begin{array}{l}\text { IPI Scale Name } \\
\text { and Number }\end{array}$} & \multirow[b]{2}{*}{ Sex } & \multicolumn{2}{|c|}{ Present Study } & \multicolumn{2}{|c|}{ Normative Data } \\
\hline & & & Mean & SD & Mean & SD \\
\hline ET & $\begin{array}{l}\text { Positive reactions } \\
\text { (4) }\end{array}$ & $\begin{array}{l}F \\
M\end{array}$ & $\begin{array}{l}44.25 \\
36.75\end{array}$ & $\begin{array}{l}6.36 \\
5.31\end{array}$ & $\begin{array}{l}40.70 \\
39.30\end{array}$ & $\begin{array}{l}8.31 \\
7.50\end{array}$ \\
\hline 0 & $\begin{array}{l}\text { Fear of failure } \\
\text { (18) }\end{array}$ & $\begin{array}{l}F \\
M\end{array}$ & $\begin{array}{l}20.75 \\
23.25\end{array}$ & $\begin{array}{l}9.30 \\
2.63\end{array}$ & $\begin{array}{l}23.74 \\
24.98\end{array}$ & $\begin{array}{r}8.95 \\
10.36\end{array}$ \\
\hline $\mathrm{ACH}$ & $\begin{array}{l}\text { Achievement oriented } \\
(16)\end{array}$ & $\begin{array}{l}F \\
M\end{array}$ & $\begin{array}{l}36.46 \\
39.50\end{array}$ & $\begin{array}{l}8.23 \\
7.94\end{array}$ & $\begin{array}{l}30.67 \\
33.95\end{array}$ & $\begin{array}{r}11.02 \\
8.11\end{array}$ \\
\hline$A G$ & $\begin{array}{l}\text { Hostile-Aggressive } \\
\text { (19) }\end{array}$ & $\begin{array}{l}F \\
M\end{array}$ & $\begin{array}{l}23.33 \\
27.00\end{array}$ & $\begin{array}{r}11.34 \\
6.58\end{array}$ & $\begin{array}{l}24.21 \\
28.71\end{array}$ & $\begin{array}{r}10.33 \\
9.56\end{array}$ \\
\hline SX & $\begin{array}{l}\text { Sexual Daydreams } \\
(20)\end{array}$ & $\begin{array}{l}F \\
M\end{array}$ & $\begin{array}{l}41.17 \\
35.00\end{array}$ & $\begin{array}{r}12.7 .4 \\
4.24\end{array}$ & $\begin{array}{l}38.80 \\
40.46\end{array}$ & $\begin{array}{l}11.52 \\
10.41\end{array}$ \\
\hline$B Z$ & $\begin{array}{l}\text { Bizarre-Improbable } \\
\text { (12) }\end{array}$ & $\begin{array}{l}F \\
M\end{array}$ & $\begin{array}{l}27.91 \\
29.25\end{array}$ & $\begin{array}{l}7.15 \\
3.86\end{array}$ & $\begin{array}{l}31.30 \\
33.20\end{array}$ & $\begin{array}{l}9.05 \\
8.63\end{array}$ \\
\hline VV & $\begin{array}{l}\text { Hallucinatory } \\
\text { Vividness (17) }\end{array}$ & $\begin{array}{l}F \\
M\end{array}$ & $\begin{array}{l}19.17 \\
21.50\end{array}$ & $\begin{array}{l}9.61 \\
8.81\end{array}$ & $\begin{array}{l}36.86 \\
25.32\end{array}$ & $\begin{array}{r}11.30 \\
9.90\end{array}$ \\
\hline
\end{tabular}

Present study: female $n=12$

$$
\text { male } n=4
$$

Normative data: female $n=274$

$$
\text { male } n=231
$$

*Normative data from 1974 sample (Segal, Huba, and Singer, 1980). These data were given by personal communication with Dr. George Huba (Huba, 1980) and may not be reproduced in any manner without express permission from the authors (Segal et al., 1980). 
CHAPTER IX

\section{DISCUSSION OF RESULTS}

Before proceeding with this discussion, a cautionary note must be made about the small $\underline{N}$ of this study. Although a sample size of 16 is moderate for sleep studies in which mentation reports are obtained from subjects in the lab, the conclusions drawn with regard to the multitrait-multimethod matrix, particularly the correlations involving IPI scores, must be tentative. However, it should be noted that significance of Pearson's $\underline{r}$ takes into account the sample size. A significance level, e.g., .05, says that for a given sample size; any $\underline{r}$ above the stated $\underline{r}$ at .05 is likely to occur by chance in 5 cases out of 100. Thus, the small $\underline{N}$ is considered when stating that an $\underline{r}$ is/is not significant.

It should also be noted that the present sample size approaches that used by Foulkes and Fleisher $(\underline{N}=20)$. Thus, comparisons between these two studies can be made in more than a tentative way.

The IPI is not only typically used with large sample sizes, but it is rarely analyzed in scale-by-scale comparisons (Huba, 1980; Huba, Aneshensel, and Singer, 1980; Singer, 1980). The more typical analysis involves collapsing scales on factors, particularly the three daydreaming styles mentioned,earlier in this paper. 
REPLICATION OF THE FOULKES AND FLEISHER STUDY

Since the present study's findings closely parallel those of the original study, and since other data gathered in this study do not contradict any of the conclusions drawn by Foulkes and Fleisher, the present study can be seen as further confirmation of the points made, by those authors:

(1) Hallucinatory mentation is well above the zero-baseline for normal subjects.

Since, in both studies, over half the subjects report the occurrence of hallucinatory mentation, it appears that this is not an extremely unusual phenomenon for the average person. When orienting the subject to the OMR, the experimenter specifically stated that the questionnaire was designed to be used with sleeping subjects, and that "You may or may not find that the questions apply too well to your waking thoughts." Thus, it cannot be considered that the subjects of the study were led to believe that they SHOULD have hallucinatory mentation. Such experiences are often looked upon as abnormal in this society, yet a high percentage of the subjects in this study were willing to admit to hallucination $(75 \%)$.

(2) Reality contact is not an appropriate criterion for the distinction between waking and sleeping mentation.

The original authors note that not only is reality contact partially or completely lost during relaxed wakefulness, but, in addition, subjects sometimes report a night dream in which reality contact is present. This is evidenced by the knowledge of the subject that "it was just a dream." The authors state: " . . it seems more accurate to state 
that reality testing is a continuous process in neither state, but is much better sustained during relaxed wakefulness than during, say, REM sleep" (Foulkes and Fleisher, 1975, p. 72).

\section{COMPARISON OF THE THREE DIFFERENT METHODS}

Means and Standard Deviations

of the Three Measures

Examination of Table $X$ reveals that the TAT stories were more negatively toned and had more negative outcomes than OMR responses. The pattern of relative values of ET and 0 are similar between the two methods, however. That is, Outcome is more positive than Emotional Tone in both TAT stories and OMR responses.

The standard deviation for OMR responses is low relative to the standard deviations of the other scales (.0924). This low standard deviation may contribute to the low reliability of $B Z$ ratings (see Table $I X$ ). That is, if few reports score more than zero on $B Z$ (as is indicated by the low standard deviation from a mean of .0676), the impact of any one rating disagreement between the judges is increased.

Al1 the means for content categories ( $A C H, A G$, and $S X$ ) were below zero (for both OMR and TAT) which indicates a high frequency of -1 ratings. Apparently, the content areas selected for coding in this study were not frequent in this sample. It might prove fruitful to examine a larger number of content categories in future validity studies. This would yield a more complete picture of fantasy production. The time and expense involved in coding reports/stories were factors which limited the scope of this study. 
Comparison of the Present Results

with Normative Data on the IPI

Most of the differences found in Table XI can be accounted for by the small $\underline{N}$ of this study. For the most part, however, patterns found in normative data can be seen in the present results.

For females, the differences in mean values between the present results and normative data ranged from .88 to 7.69 . The lowest difference was on Hostile Aggressive Daydreams ( $A G)$. The highest difference was on Hallucinatory Vividness (VV); however, it should be noted that the difference did not exceed the standard deviation of the normative data. None of the differences found exceeded the standard deviation of the normative sample. Thus the present sample of females appears to resemble the normative sample.

For males, it was also found that the differences in means between the present sample and the normative sample did not exceed the standard deviation of the normative sample on any scale. The lowest difference in means was on Fear of Failure (0), yielding a value of 1.73 , with males in the present sample scoring lower than males in the normative sample. The highest difference was 5.56 on Achievementoriented Daydreams $(A C H)$ with males in the present sample scoring higher than those in the normative sample.

With regard to patterns of sex differences on means, the present results paralleled those of the normative study on most of the scales. However, in the present study, females scored higher on Scale 20 (Sexual Daydreams) than did the males. This is opposite the findings of the normative study. The impact of any one score is greater in a smaller sample which may account for the difference found here. One 
female subject in the present study scored the maximum points possible on Scale 20 (60 is maximum). This extreme score raised the mean for females and may account for the large mean score (relative to males). It may also be that female subjects were more inclined to report sexual daydreams to the female experimenter.

Only one other discrepancy in the relative means of males and females occurred. In the present study, males scored higher than females on Hallucinatory Vividness (VV), which is opposite the results of the normative study. The absolute value of the difference in means between males and females is approximately the same in both studies (2.33 for the present study and 1.54 in the normative study). Considering the size of this difference, the relative values of male and female means seems small, and may be accounted for by the small $\underline{N}$ of the present study.

Given the above findings, the sample of the present study resembled, in most respects, the normative sample reported by Huba et al. (1977).

Convergent and Discriminant Validity on the Multitrait-multimethod Matrix

Three aspects of a multitrait-multimethod matrix are noteworthy: (1) validity diagonals, (2) heterotrait-monomethod triangles, and (3) heterotrait-heteromethod triangles (Campbell and Fiske, 1959).

The validity diagonals consist of the correlation coefficients for each trait as measured by an independent method. Another way of viewing the validity diagonals is to refer to them as monotrait-heteromethod correlations. The values in these diagonals should be significantly 
above zero in order to state that any two methods demonstrate convergent validity on a given trait (Campbel1 and Fiske, 1959). Also, the values in the validity diagonals should be higher than the values in the columns and rows in which the validity coefficient occurs. Otherwise, even a significant monotrait-heteromethod correlation cannot be considered sufficiently discriminant from other traits (Campbell and Fiske, 1959).

A third comparison involving validity diagnonals is important, and is considered to be another indicator of discriminant validity. The values in the validity diagonals should be higher than the values found in the heterotrait-monomethod triangles adjacent to them. In other words, a trait should correlate more highly with an independent effort to measure that trait, than it does with other traits which employ the same method (Campbell and Fiske, 1959)..

Another measure of discriminant validity can be found by examining the pattern of correlation coefficients in the heterotrait-heteromethod triangles. This pattern should be similar to that found in the heterotrait-monomethod triangles in order to conclude that discriminant validity exists. in the matrix (Campbell and Fiske, 1959).

Figure 1 is a simplified multitrait-multimethod matrix which should help the reader to make the above comparisons on the full matrix (Table VII).

In Table VII, the significant correlations in the validity diagonals are smaller in number than those found in the heterotraitheteromethod triangles. Thus, it can be said that al though convergent validity exists between the three measures for some traits, discriminant 
Method $1 \quad$ Method $2 \quad$ Method 3

\begin{tabular}{lllllllllll} 
Traits & $A$ & $B$ & $C$ & A & B & C & & A & B & C \\
\hline
\end{tabular}

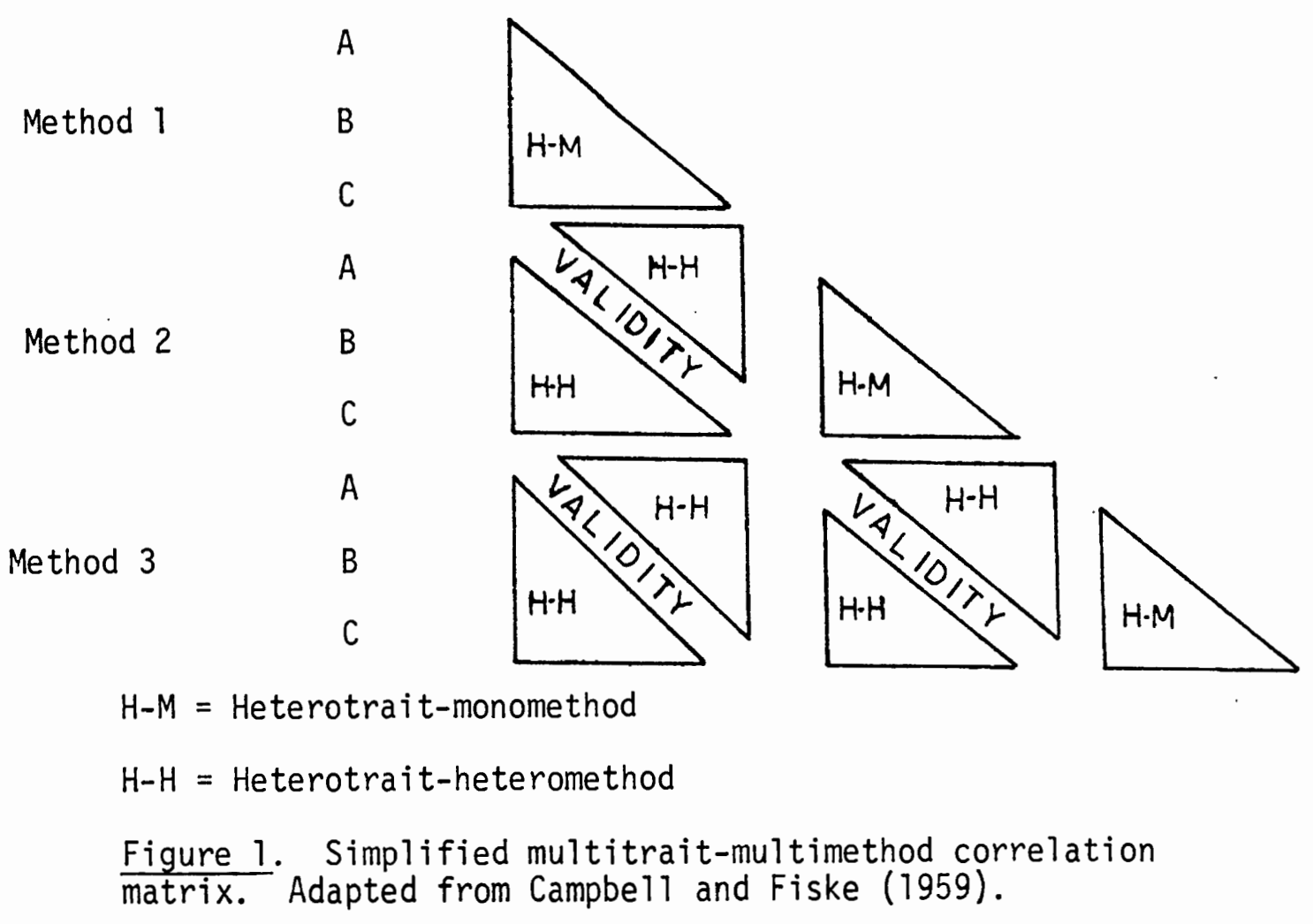

validity is not obtained. None of the significant correlations in the validity diagonals occurs in the absence of other significant correlations in the same row or column. In other words, even if a significant relationship exists between two methods of measuring any given quality of fantasy, significant correlations also exist between: (1) other qualities measured by the same method, and (2) other qualities measured by other methods.

Further evidence of the lack of convergent validity of the three methods is evidenced by the low number of significant correlations in the validity diagonals. There are fewer significant correlations in 
the validity diagonals than there are insignificant correlations in those diagonals.

Comparison of the three heterotrait-monomethod triangles reveals that none of the significant correlations found in any given triangle is found in all three triangles. Thus, the requirement that the heterotrait-monomethod and the heterotrait-heteromethod triangles exhibit similar patterns of correlation is not met.

Based on the above comparisons, neither extensive convergent or discriminant validity is demonstrated among the three measures of fantasy employed in this study. Thus, the validity of comparing research findings which utilize different measures of waking fantasy is in question. Of the three models described earlier in this paper, none can be considered veridical over any other based on the comparison of research which utilizes divergent assessment techniques of waking fantasy. Again, these findings must be considered tentative in light of the small sample size and further research with larger samples should be undertaken before asserting this conclusion more strongly.

Other variables may also affect the correlations obtained. Most notable are these: (1) the effect of having verbalized daydreams (in the OMR) on subsequent testing, particularly the IPI; (2) the tendency of subjects to report mentation which is socially desirable and to suppress reporting undesirable thoughts; and (3) the tendency for some scales of the IPI to cluster on the three factors described earlier. With regard to the contamination of subsequent testing by the OMR, it may be the case that subjects had not considered the ir daydreams before undergoing the OMR. As one subject stated, "I never 
realized that I spent so much time thinking about men before!" This subject obtained the maximum points on the IPI scale of Sexual Daydreams (maximum $=60)$. That is, she endorsed items which state a high frequency of heterosexual daydreams. Whether or not she would have responded on the IPI in the same way had she not undergone the OMR is impossible to say. However, her comment during the OMR regarding her surprise at the frequency of sexual daydreams indicates that she underwent a changed perspective of her own daydream habits.

The second point, regarding social desirability, is well illustrated by another subject's remarks during the OMR. This subject is a 34-year-old male, psychology major. He stated, in response to Question 11 (What can you remember of the sequence of thoughts that led up to this experience?):

I got engrossed in this lab. Not the lab itself, but the experiment. Playing Russian Roulette with a person's mind. You broke in at a certain moment--you would break in--when who knows what was on your mind. I was just at a point imagining what this game of Russian Roulette would do if you--if your thoughts were disgusting or something. Like a fantasy or something you keep to yourseif. Should I tell? Maybe I better think of something quick. And I did.

If this tendency occurred in all subjects, it might explain the lack of aggressive mentation, as well as the low frequency of sexual imagery.

With regard to the factor loadings of the IPI scales, certain correlations can be expected to be significant, particularly between scales which load highly on the same factor. For example, AG (HostileAggressive) and 0 (Fear of Failure) both load on Factor $S_{2}$ (.56 and .60, respectively). They also correlate to a highly significant degree in the heterotrait-monomethod triangle of the matrix (Table VII). A Pearson's $\underline{r}$ of .716 was obtained between those two traits, a value 
which is significant at the .01 level. Thus, the correlations involving any IPI trait must be considered in light of the factor loadings presented in Table XII, which lists data obtained in a study of 1,095 college students (Huba, Segal, and Singer, 1977).

TABLE XII

FACTOR LOADINGS OF IPI SCALES ON THREE SECOND-ORDER FACTORS $(\underline{N}=1,095)$

\begin{tabular}{c|l|c|c|c|}
\hline \hline Label & IPI Scale Name and Number & $\mathrm{S}_{1}$ & $\mathrm{~S}_{2}$ & $\mathrm{~S}_{3}$ \\
\hline ET & Positive Reactions (4) & .52 & .06 & .23 \\
0 & Fear of Failure (18) & -.14 & .60 & .18 \\
ACH & Achievement-oriented (16) & .22 & .39 & .06 \\
AG. & Hostile-Aggressive (19) & .01 & .56 & .18 \\
SX & Sexual Daydreams (20) & .39 & .16 & .24 \\
BZ & Bizarre-Improbable (12) & .02 & .28 & .17 \\
WV & Hallucinatory Vividness (17) & .27 & .52 & .26 \\
\hline
\end{tabular}

SOURCE: Huba, Segal, and Singer (1977).

Consideration of Previous Research in Light of Present Results

As outlined earlier, many research efforts which bear on the relationship between waking and sleeping mentation have used different assessment techniques of waking fantasy. A contention was made that the use of divergent methodologies makes it difficult to compare research results. Further, it was contended that an examination of the convergent and discriminant validity of the three measures of waking fantasy might enable researchers partially to account for divergent research results. 
The results of the present study have indicated that neither extensive covergent validity nor extensive discriminant validity is demonstrated among the three measures employed to assess waking fantasy. It seems appropriate at this point to reconsider specific examples of research which have used the IPI and the TAT in light of the findings displayed in Table VII. Two studies which were cited earlier are appropriate for this consideration. Since the OMR has not been used in any studies, besides the present one and Foulkes and Fleisher (1975), it will not be considered here.

Use of the IPI. In a study supporting the continuum model, Starker (1973) found significant correlations between-dreams recalled in diaries and several scales of the IPI. In that study, dream bizarreness was positively correlated to a significant degree $(p<.05)$ with IPI Bizarreness (Scale 12). Examination of Table VII reveals that IPI-BZ did not obtain significance with either TAT-BZ or OMR-BZ (.269 and .232 respectively). Thus, had Dr. Starker used either the TAT or the OMR as a measure of waking fantasy biazarreness, he might not have obtained a significant correlation between night dreams and daydreams.

Dreams were also coded for Affective Polarity in that study. The scale for Affective Polarity is analogous to Emotional Tone in the present study. A low score on Affective Polarity corresponds to negative affect and a high score corresponds to positive affect. In Dr. Starker's study, Affective Polarity was negatively correlated to a significant degree $(p<.05)$ with IPI Fear of Failure (Scale 18) and IPI Hostile-Aggressive Daydreams (Scale 19). In other words, the more 
positive affect in night dreams, the less Fear of Failure and HostileAggression exhibited in daydreams.

Examination of Table VII indicates: (1) IPI-O (Fear of Failure) was positively correlated with OMR-0 $(p<.02)$ and negatively correlated with TAT-O $(p<.05)$; and (2) IPI-AG (Hostile-Aggressive) was not significantly correlated with either OMR-AG or TAT-AG. Thus, with regard to IPI-0, Dr. Starker's findings might have been similar if he had used OMR responses as a measure of waking fantasy, since IPI-0 is positively correlated with OMR-0. Had he used the TAT, his findings might have been significant, but in the opposite direction, since IPI-0 was negatively correlated with TAT-0 $(p<.05)$.

With regard to IPI-AG and Affective Polarity of dreams, his findings might have been insignificant, since IPI-AG did not obtain significant correlations with either OMR-AG or TAT-AG (.163 and -.021 respectively).

It should be kept in mind that all IPI scales measured in Dr. Starker's study also correlated significantiy with other traits in the heterotrait-heteromethod and/or heterotrait-monomethod triangles of Table VII of this study. The lack of discriminant validity of IPI trait comparisons might reduce the interpretive power of any significant findings. This might be particularly true when the scales are used independently of the factors on which they load (see Table XII). As mentioned earlier, use of the individual scales is not considered particularly valid (Huba, 1980; Huba, Aneshensel, and Singer, 1980; Singer, 1980). 
Use of the TAT. In a study supporting the independent-processes model, Foulkes et al. (1966) found significant positive correlations between Sleep-onset Dreamlike Fantasy (SO-DF) and the following traits of waking fantasy as measured by the TAT: Aggression. $(p<.01)$, Sex $(p<.05)$, and Hedonic Tone $(p<.05)$. The latter measure is comparable to Emotional Tone in the present study, but is scored in the opposite direction; i.e., a high score indicates unpleasant affective tone and a low score indicates a pleasant affective tone. REM-DF was positively correlated with TAT Aggression $(p<.01)$ and TAT Hedonic Tone $(p<.05)$. The DF ratings were made on reports obtained from subjects who were physiologically monitored during sleep in the lab and awakened during SO and REM periods.

Examination of Table VII reveals that of the traits measured by Dr. Foulkes, only one, TAT Sex, exhibits convergent validity with the IPI $(p<.02)$. Convergent validity is not present between any of the other traits, as measured by the IPI or the OMR. Thus, use of the IPI might have yielded similar results only with respect to sexual content. Use of the OMR might have yielded insignificant results on all traits.

The comments which were made about Dr. Starker's study with respect to discriminant validity also apply here. That is, the traits measured (Aggression, Sex, and Hedonic Tone) all obtained significant correlation with traits in the heterotrait-heteromethod triangles and/or in the heterotrait-monomethod triangles. Thus, discriminant validity was not found for these traits in the present study, which reduces the interpretive power of any significant findings on these traits. 


\section{CHAPTER $X$}

\section{SUMMARY AND CONCLUSIONS}

Neither the convergent nor the discriminant validity of the measures and rating scales used in this particular study was extensive enough to justify equating the three methods of daydream assessment. Convergent validity indicates that findings would be similar if a different measure had been used in a given study (i.e., the measure that displays convergent validity with the one actually used). Discriminant validity adds to the overall validity index of a measure and enables the researcher to state, with more assurance, that a measure is a valid indicator of the presence of a particular trait and that it is not an artifact of the technique used (Campbell and Fiske, 1959). When the researcher cannot demonstrate discriminant validity of his measure, the power of interpretation of results is diminished.

As mentioned earlier, it might be appropriate to begin research which compares night dreams with daydreams in the same subjects, using several methods of assessing each state. Dream diaries, as well as lab sessions, might be used to assess night dreams, while daydreams could be assessed using any of numerous methods and/or rating scales. It would be important, however, in light of the present findings, to use several different methods to assess daydreams in order to demonstrate convergent and discriminant validity. 
The findings of the present study have indicated some trends which should be followed up with larger sample sizes and with more varied content analysis. Some aspects of daydreaming which might be fruitful to consider include: olfactory, auditory, and kinesthetic experiences; some of the more traditional content areas of the TAT (e.g., nurturance, power, affiliation, etc.); and Rorschach $\underline{M}$. With a large sample size and a large number of traits, factor analysis or multiple regression might be employed.

Personality and life style correlates of daydreaming are two more avenues which might be interesting to pursue in connection with convergent and discriminant validity studies of daydreaming. It may be that for some persons, two measures present an equivalent picture of daydream habits, while for others the two measures are not equivalent. of course, the more measures used, the more expense is incurred and the more time it takes to complete research. The same is true for sample size: as numbers go up, so do costs in time and money. Case studies might be one way to approach the issues raised above without incurring large costs. However, if the researcher expects his subjects to devote large amounts of time to the study, he must be prepared to recompense them appropriately. Thus, a case study approach might cost as much as a normative size sample, but would allow more traits to be examined in greater depth.

In summary, until more information is gathered on the convergent and discriminant validity of measures currently in use to assess daydreaming (as well as night dreaming), researchers and theoreticians 
should use caution when comparing the results of research which utilizes divergent assessment techniques. 
REFERENCES 


\section{REFERENCES}

Anderson, J. Individual differences in imaginal and verbal information processing abilities. Unpublished master's thesis, Portland State University, $19,80$.

Antrobus, J. S. Editor's Commentary to Chapter 4. In A. Arkin, J. S. Antrobus, \& S. J. Ellman (Eds.), The mind in sleep: Psychology and psychophysiology. Hillsdale: Lawrence Erlbaum \& Associates, 1978.

Arkin, A. M. Introduction. In A. Arkin, J. S. Antrobus, \& S. J. Ellman (Eds.), The mind in sleep: Psychology and psychophysiology. Hillsdale: Lawrence Erlbaum \& Associates, 1978.

Aserinsky, E., \& Kleitman, N. Regularly occurring periods of eye motility and concomitant phenomena during sleep. Science, 1953, 118, 341-344.

Atkinson, J: (Ed.). Motives in fantasy, action and society. Princeton: D. Van Nostrand Company, Inc., 1958.

Baekland, F., Resch, R., \& Katz, D. Presleep mentation and dream reports: Cognitive style, contiguity to sleep, and time of night. Archives of General Psychiatry, 1968, 19 (3), 300-311.

Barron, F. Threshold for the perception of human movement in inkblots. Journal of Consulting Psychology, 1955, 19, 33-38.

Bijou, S. W. \& Kenney, D. T. The ambiguity of TAT cards. Journal of Consulting Psychology, 1951, 15, 203-209.

Brown, J. N. \& Cartwright, R. D. Locating NREM dreaming through instrumental responses. Psychophysiology, 1978, 15 (1), 35-39.

Campbe11, D. T. \& Fiske, D. W. Convergent and discriminant validation by the multitrait-multimethod matrix. Psychological Bulletin, $1959,56,81-105$.

Cartwright, R. D. Sleep fantasy in normal and schizophrenic persons. Journal of Abnormal Psychology, 1972, 80 (3), 275-279.

Cartwright, R. D. A primer on sleep and dreaming. Reading: AddisonWesley Pub. Co., 1978. 
Cartwright, R. D. \& Kaszniak, A. The social psychology of dream reporting. In A. Arkin, J. S. Antrobus, \& S. J. Ellman, The mind in sleep: Psychology and psychophysiology. Hillsdale: Lawrence Erlbaum \& Associates, 1978.

Cartwright, R. D., Monroe, L. J., \& Palmer, C. Individual differences in response to REM deprivation. Archives of General Psychiatry, 1967, 16, 297-303.

Cartwright, R. D. \& Ratzel, R. W. Effects of dream loss on waking behaviors. Archives of General Psychiatry, 1972, 27, 277-280.

Cohen, D. B. Frequency of dream recall estimated by three methods and related to defense preference and anxiety. Journal of Consulting and Clinical Psychology, 1969, 33, 661-667.

Cohen, D. B. Dream recall and total sleep time. Perceptual and Motor Skills, 1972, 34, 456-458.

Cohen, D. B. Sex role orientation and dream recall. Journal of Abnormal Psychology, 1973, 82, 246-252.

Cohen, D. B. Toward a theory of dream recall. Psychological Bulletin, 1974,81 (2), 138-154.

Corballis, M. C. \& Beale, I. L. The psychology of left and right.

Hillsdale: Lawrence Erlbaum \& Associates, 1976.

Eron, L. D. A normative study of the Thematic Apperception Test. Psychological Monographs, 1950, 64 (Whole No. 315).

Feshbach, S. The drive-reducing function of fantasy behavior. Journal of Abnormal and Social Psychology, 1955, 50, 3-11.

Fiss, H., Klein, G. S., \& Bokert, E. Waking fantasies following interruption of two types of sleep. Archives of General Psychiatry, $1966,14,543-551$.

Foulkes, D. Dream reports from different stages of sleep. Journal of Abnormal and Social Psychology, 1962, 65, 14-25.

Foulkes, D. Dream-like Fantasy Scale: A rating manual. Psychophysiology, $1971, \underline{7}, 335-336$.

Foulkes, D. \& Fleisher, S. Mental activity in relaxed wakefulness. Journal of Abnormal Psychology, 1975, 84 (1), 66-75.

Foulkes, D. \& Rechtschaffen, A. Presleep determinants of dream content: Effects of two films. Perceptual and Motor Ski1ls, 1964, 19, 983-1005. 
Foulkes, D., Spear, P. S., \& Symonds, J. D. Individual differences in mental activity at sleep onset. Journal of Abnormal Psychology, 1966,71 (4), 280-286.

Foulkes, D. \& Vogel, G. Mental activity at sleep onset. Journal of Abnormal Psychology, 1965., 70 (4), 231-243.

Freud, S. The unconscious. In The standard edition of the complete psychological works of Sigmund Freud, Vol. 14. (J. Strachey, Ed. and trans.) London: The Hogarth Press and The Institute of Psychoanalysis, 1935. (Originally published, 1915)

Freud, S. An outline of psychoanalysis. (J. Strachey, Ed. and trans.) New York: W. W. Norton \& Company, Inc., 1969. (Originally published, 1949)

Goodenough, D. R., Shapiro, A., Holden, M., \& Steinschriber, L. A comparison of "dreamers" and "nondreamers." Journal of Abnormal and Social Psychology, 1959, 83, 32-44.

Gordon, R. An experiment correlating the nature of imagery with performance on a test of reversal of perspective. British Journal of Psychology, 1950, 41, 63-67.

Gordon, H. A comparative study of dreams and responses to the Thematic Apperception Test. I. A need-press analysis. Journal of Personality, 1953, 22, 234-253.

Hall, C. S. \& Lindzey, G. Theories of personality. New York: John Wiley \& Sons, Inc., 1970.

Hauri, P. Effects of evening activity on early night sleep. Psychophysiology, 1968, ㄴ, 267-277.

Holt, R. R. Imagery: The return of the ostracized. American Psychologist, 1964, 19, 254-264.

Huba, G. Personal communication by telephone, July 15, 1980.

Huba, G. J., Aneshense1, C. S., \& Singer, J. L. Development of scales for three second-order factors of inner experience. Unpublished manuscript, 1980. (Available from George J. Huba, Dept. Psychology, University of California, $405 \mathrm{Hilgard}$ Avenue, Los Angeles, CA 90024.)

Huba, G. J., Segal, B., \& Singer, J. L. Consistency of daydreaming styles across samples of college male and female drug and alcohol users. Journal of Abnormal Psychology, 1977, 86, 99-102.

Kagan, J. The measurement of overt aggression from fantasy. Journal of Abnormal and Social Psychology, 1956, 52, 390-393. 
Klinger, E. Structure and function of fantasy. New York: Wiley, 1972.

Lubin, B. Some effects of set and stimulus properties on TAT stories. Journal of Projective Techniques, 1960, 24, 11-16.

Lubin, B. Judgments of adjustment from TAT stories as a function of experimentally altered sets. Journal of Consulting Psychology, $1961,25,249-252$.

McClelland, D. C. The achieving society. Princeton: D. Van Nostrand Company, Inc., 1967.

McClelland, D. C., Atkinson, J. W., Clark, R. A., \& Lowe11, E. L. The achievement motive. New York: Irvington Publishers, Inc., $1 \overline{976 .}$

Megaree, E. I. (Ed.). Research in clinical assessment. New York: Harper \& Row, PubTishers, 1966.

Murray, H. A. Explorations in personality. New York: Oxford University Press, 1938.

Murray, H. A. Thematic Apperception Test manual. Cambridge: Harvard University Press, 1943.

Murstein, B. I. The relationship of stimulus ambiguity on the TAT to the productivity of themes. Journal of Consulting Psychology, $1958,22,348$.

Murstein, B. I. Assumptions, adaption level and projective techniques. Perceptual and Motor Skills, 1961, 12, 107-125.

Murstein, B. I. Theory and research in projective techniques (emphasizing the Thematic Apperception Test). New York: John Wiley \& Sons, Inc., 1963.

Oakland, J. A. Note on the social desirability response set in Singer's Daydreaming Questionnaire. Psychological Reports, 1968, 23, 689-690.

Ornstein, R. E. Psychology of Consciousness. New York: Harcourt, 1972.

Page, H. A. Studies in fantasy: Daydreaming frequency and Rorschach scoring categories. Journal of Consulting Psychology, 1957, $21,111-114$.

Paivio, A. \& Foth, D. Imaginal and verbal mediators and noun concreteness in paired associate learning: The elusive interaction. Journal of Verbal Learning and Verbal Behavior, 1970, 9 , 384-390. 
Paivio, A., Yuille, J. C., \& Madigan, S. A. Concreteness, imagery and meaningfulness values for 925 nouns. Journal of Experimental Psychological Monographs, 1968, 76 (1), pt. 2, 1-25.

Pivik, T. \& Foulkes, D. NREM mentation: Relation to personality orientation time, and time of night. Journal of Consulting and Clinical Psychology, 1968, 32, 144-151.

Rechtschaffen, A. \& Kales, A. (Eds.). A manual of standardized terminology, techniques and scoring systems for sleep stages of human subjects. National Institute of Health Publication \#204, Washington, D.C.: U. S. Government Printing Office, 1968.

Reitman, W. R. \& Atkinson, J. W. Some methodological problems in the use of thematic apperceptive measures of human motives. In $\mathrm{J}$. W. Atkinson (Ed.), Motives in fantasy, action and society. Princeton: D. Van Nostrand, 1958.

Richardson, A. Mental imagery. London: Routledge and Kegan Paul, 1969.

Richardson, A. Voluntary control of the memory image. In P. Sheehan (Ed.), The nature and function of imagery. New York: Academic Press, 1972 .

Rorschach, H. Psychodiagnostics. New York: Grune and Stratton, 1942.

Sarason, S. B. Dreams and Thematic Apperception Test stories. Journal of Abnormal and Social Psychology, 1944, 39, 486-492.

Segal, B., Huba, G. J., and Singer, J. L. Drugs, daydreaming and personality: A study of college youth. Hillsdale: Lawrence ErTbaum \& Associates, 1980. (Not yet released.)

Sheehan, P. W. (Ed.). The nature and function of imagery. New York: Academic Press, 1972.

Singer, J. L. Delayed gratification and ego development: Implications for clinical and experimental research. Journal of Consulting Psychology, 1955, 19, 259-266.

Singer, J.L. The experience type: Some behavioral correlates and theoretical implications. In M. R. Rickers-Ovsiankina (Ed.), Rorschach psychology. New York: Wiley, 1960.

Singer, J. L. Daydreaming: An introduction to the experimental study of inner experience. New York: Random House, 1966.

Singer, J. L. The inner world of daydreaming. New York: Harper and Row, Publishers, Inc., 1975.

Singer, J. L. Personal communication by telephone, July 15, 1980. 
Singer, J. L. \& Antrobus, J. S. A factor-analytic study of daydreaming and conceptually-related cognitive and personality variables. Perceptual and Motor Skills, 1963, 17, 187-209.

Singer, J. L. \& Antrobus, J. S. Daydreaming, imaginal processes and personality: A normative study. In P. W. Sheehan (Ed.), The nature and function of imagery. New York: Academic Press, 1972.

Singer, J. L. \& McCraven, V. Some characteristics of adult daydreaming. Journal of Psychology, 1961, 51, 151-164.

Singer, J. L. \& McCraven, V. Patterns of daydreaming in American subcultural groups. International Journal of Social Psychiatry, $1962, \underline{8}, 272-282$.

Singer, J. L. \& Rowe, R. An experimental study of some relationships between daydreaming and anxiety. Journal of Consulting Psychology, $1962,26,446-454$.

Singer, J. L. \& Schonbar, R. A. Correlates of daydreaming: A dimension of self-awareness. Journal of Consulting Psychology, 1961, 25 (1), $1-6$.

Starker, S. Aspects of inner experience: Autokinesis, daydreaming, dream recall and cognitive style. Perceptual and Motor Skills, $1973,36,663-673$.

Starker, S. Daydreaming styles and nocturnal dreaming. Journal of Abnormal Psychology, 1974, 83 (1), 52-55.

Starker, S. Daydreaming styles and noctural dreaming: Further observations. Perceptual and Motor Skills, 1977, 45, 411-418.

Starker, S. \& Hasenfeld, R. Daydream styles and sleep disturbance. Journal of Nervous and Mental Disease, 1976, 163, 391-400.

Tart, C. T. (Ed.). Altered states of consciousness. New York: Anchor Books, 1972.

Thorndike, E. L. \& Lorge, I. The teacher's word book of 30,000 words. New York: Teachers' College, Columbia University, Bureau Publications, 1944.

Tomkins, S. Affect, imagery, and consciousness. Vol. I. New York: Springer, 1962.

Verdone, P. Temporal reference of manifest dream content. Perceptual and Motor Skil1s, 1965, 20, 1253-1268.

Vogel, G. W. Sleep onset mentation. In A. Arkin, J. S. Antrobus, \& S. J.Ellman (Eds.), The mind in sleep: Psychology and psychophysiology. Hillsdale: Lawrence Erlbaum \& Associates, 1978. 
Voge1, G., Foulkes, D., \& Trosman, H. Ego functions and dreaming during sleep onset. Archives of General Psychiatry, 1966, 14, 238-248.

Weisskopf, E. A. A transcendence index as a proposed measure in the Thematic Apperception Test. Journal of Psychology, 1950, 29, 379-390.

Witkin, H. A., Dyk, R. B., Patterson, H. F., Goodenough, D. R., \& Karp, S. A. Psychological differentiation. New York: Wiley, 1962.

Yuille, J. C. \& Paivio, A. Imagery and verbal mediation instructions in paired-associate learning. Journal of Experimental Psychology, $1968,78(3), 436-441$. 
APPENDICES 
APPENDIX A

ORIENTATION SCRIPT--OMR

Our studies usually involve waking subjects up from a state of sleep and asking them to report mental experiences which occurred just prior to their arousal. Today you are being asked to serve in a study which is a waking control for these sleep experiments. The difference is that we are asking you to relax, but stay awake, during the recording session.

As in nighttime studies, we will call you at various times during the recording period and ask you for an account of the mental experience passing through your mind before the experimenter's call. If you do not wish to report your thoughts for any reason, that's okay. Just tell the experimenter that you would rather not talk about the mental experience.

We do two kinds of sleep studies. One type involves comparing reports obtained from different stages of sleep, of which there are five...

(Experimenter describes the progression of sleep stages, NREM $i-4$, and REM.)

Since sleep stages are physiological events with a duration of many minutes, subjects' reports of their mental experiences do not have to be identified precisely as having occurred just before their awakening. Sometimes the thoughts cover several minutes, or long periods of time before the awakening, as in the report of a long, involved dream.

The other kind of sleep study attempts to correlate mental experiences with much more brief physiological events, like some quality of brain wave activity. In these studies, subjects are asked to try to recount only the very last mental experience they had before their awakening, since only that one could meaningfully be correlated with a physiological event which happened only a second or two before the awakening.

The present study is a control for both kinds of sleep study. Thus, when we call your name today and ask you for an account of your waking mental experiences, we want you to describe only the very last thing in your mind before you heard your name called. The experimenter will ask you a series of questions about that brief mental experience. After these questions, the experimenter will ask you to relate the thoughts which led up to the mental experience. Again, if you do not 
wish to talk about any thought, or any aspect of a thought, just tell the experimenter. She will not question you about this.

Since this is a control for sleep experiments, the interview we will use is the same one we use when subjects tell us their dreams. Thus, its questions may not always apply too well to the kinds of experiences you have when awake.

(This script is adapated from Foulkes and Fleisher, 1975.) 
APPENDIX B

INTERVIEW--OMR

1. What was the very last thing going through your mind just before I called you?

2. Was it visual? What could you see? Were you simply seeing something without reflecting on it or were you actively thinking or reflecting about what you were seeing?

3. Has it auditory? What could you hear? Were you simply hearing something without reflecting on it or were you actively thinking or reflecting about what you were hearing?

4. Which type of imagery predominated, what you could see or what you could hear?

5. Did you have any feelings or emotions during this experience?

6. (Omitted for experiences not involving imagining, such as eyes-open perceptions or unfanciful thoughts) At the time you sensed these things, did you feel that they were really happening, or did you know at the time that these were just things that you were making up in your mind?

7. At the time you thought these things, were you aware that you were here in the laboratory, lying in your bed?

8. Did you feel like you were voluntarily controlling the nature of your thoughts in the sense that you could stop them if you wanted to, or was it more like they were just "happening" to you?

9. How well would you say that you can remember exactly what was happening before I called you: very well, fairly well, or not too well at all?

10. Just before I called you, would you say that you were: awake and alert, awake and relaxed, awake but drowsy, drifting off to sleep, in light sleep, or in deep sleep?

11. What can you remember of the sequence of thoughts which led up to the brief mental experience you have just described?

(This questionnaire is adapted from Foulkes and Fleisher, 1975.) 
APPENDIX C

REGRESSIVITY--OMR

Content is rated as non-regressive if the mentation is plausible, realistic, coherent, and undistorted, whether it consists of verbal thoughts or visual images. Content is rated regressive only by the presence of one or more of six categories:

1. Single, isolated images, such as the number 2,081 hanging in mid-air; or a meaningless pattern, such as oblique lines as seen on a poorly tuned TV screen

2. An incomplete scene or bits and pieces of a scene, e.g., the subject reports that he was in the process of constructing a lab scene, but it was incomplete, i.e., people and objects not yet in their proper places

3. Bizarre, inappropriate, or distorted images, e.g., the image of tiny, hairy people sitting inside the chest cavity

4. Bizarre sequence or superimposition of images, e.g., subject reports seeing a train station on which was superimposed an image of strawberries

5. Dissociation of thought and image, e.g., subject reports he was driving a car and simultaneously thinking about a problem in linguistics

6. Magical, omnipotent thinking, e.g., subject reports that he was a giant waving his hand over an entire town, and with each wave of his hand the lights of the town became dimmer 1966.)

(Criteria and examples adapted from Vogel, Foulkes, and Trosman, 


\section{APPENDIX D}

\section{REALITY CONTACT--OMR}

In tabulating the function of maintaining contact with external reality, the answers to questions 6,7 , and 8 of the interview included in Appendix B are used:

6. (Omitted for experiences not involving imagining, such as eyes-open perceptions or unfanciful thoughts) At the time you sensed these things, did you feel that they were really happening, or did you know at the time that these were just things that you were making up in your mind?

7. At the time you thought these things, were you aware that you were here in the laboratory, lying in your bed?

8. Did you feel like you were voluntarily controlling the nature of your thoughts in the sense that you could stop them if you wanted to, or was it more like' they were just happening to you?

These questions assess the subject's ability to maintain volitional control, orientation to time and place, and the discrimination between an internal and an external event. Contact with reality is classified intact if all these abilities are unimpaired; partially lost if some but not all of these abilities are impaired; and completely lost if all these abilities are impaired.

(These criteria are adapted from Vogel, Foulkes, and Trosman, 1966, and are also drawn from Foulkes and Fleisher, 1975.) 


\section{APPENDIX E}

\section{RATING SCALE FOR EMOTIONAL TONE--OMR AND TAT}

-2 Very sad or negative. May include feeling of complete failure, submission to fate, death, murder, suicide, illicit sex, violence, revenge, aggressive hostility, severe guilt, complete hopelessness.

-1 Sad or negative. May include conflict with attempt at adjustment, rebellion, fear, worry, departure, regret, illness, physical exhaustion, resignation toward death, loneliness.

0 Neutral. Includes description only, lack of affect, balance of positive and negative feelings, routine activities, impersonal reflection.

+1 Happy. Includes aspiration, desire for success and doubt about outcome, compensation for limited endowment. Description with cheerful feeling, reunion with friends, contentment with world, feeling of security.

+2 Very happy. Includes justifiably high aspiration, complete satisfaction and happiness, reunion with loved ones.

(Adapted from Eron, 1950.) 


\section{APPENDIX F}

\section{RATING SCALE FOR OUTCOME--OMR AND TAT}

-2 Very negative. Includes complete failure, submission to fate, death, murder, suicide, extreme punishment, extreme remorse.

-1 Negative. Includes some frustration, incomplete success in attaining goal, goal attained at expense of happiness, disappointment to friends and family, acceptance of unsatisfactory situation or submission to authority.

0 Neutral. Includes continuation of ordinary situation, or a balance of happy and unhappy situations.

+1 Positive. Includes moderate success, reunion with friends, recovery from temporary disability or depression, happiness in the success of others.

+2 Very positive. Includes great success, discovery, and/or happiness, extreme contentment, marital bliss, unusual good fortune, reunion with loved ones.

(Adapted from Eron, 1950.) 
APPENDIX G

RATING SCALE FOR ACHIEVEMENT, AGGRESSION,

AND SEX--OMR AND TAT

The first judgment is whether or not the story contains imagery related to the theme. Specific criteria for each theme are defined after complete presentation of this scoring system.

+1 Imagery related to the theme is present. AchI, AggI, and SI denote this category.

0 Imagery related to the theme is not present, according to criteria, but the report contains some reference to the theme. TI denotes this category for all themes.

-1 Imagery unrelated to the theme is present with no imagery related to the theme present. UI denotes this category.

Any report obtaining $a+1$ (AchI, AggI, SI) rating is scored for the following categories:

A. Stated need/motive for the theme (N). Someone in the story/ report states the desire to reach an achievement goal, to engage in hostile or aggressive acts, or to engage in a sexual encounter. One point is added for the presence of this stated need, regardless of the frequency of its statement.

B. Instrumental activity (I). Overt or mental activity by one or more characters in the report indicating that something is being done about attaining an achievement goal, or aggressive or sexual release or expression of desire. Mental activity refers to planning or thinking about how to achieve the desired state or action. One point is added for the presence of this category, again regardless of frequency.

C. Thema Status (AchTh, AggTh, STh). One point is added when the theme is elaborated to such an extent that it becomes the central plot or theme of the story/report.

Achievement is defined as meeting one or more of the following criteria:

1. Competition with a standard of excellence. One of the characters is engaged in some activity (other than fighting) where winning or doing well as, or better than, others is a 
primary concern, e.g., getting a grade in school, winning a contest of academic or physical skill (essay contest, horse show, gymnastics meet, etc.).

2. Unique accomplishment. One of the characters is involved in accomplishing other than a run-of-the-mill daily task which will mark him/her as a personal success, e.g., inventions, artistic creations, building a boat or plane, etc.

3. Long-term involvement. One of the characters is involved in the attainment of a long-term goal, e.g., being a success in life, becoming a good machinist, doctor, lawyer, mother, father, etc. Reference must be made to a long-term goal. For example, a subject might report: "A woman is sewing a dress for her little girl. It is important for her to be a good mother." Without the last sentence, the long-term goal of being a good mother could not be inferred, but as it stands, this report would be scored +1 AchI.

Aggression is defined as any reference to the desire to verbally or physically attack or injure a person or object. Also included are statements of feeling angry, hostile, or mad. E.g., a subject might report: "He was so angry he felt like punching his fist through the wal1." This report should be scored +1 Agg I since it expresses angry feeling as well as a desire to engage in a physical attack upon an object.

Sex is defined as any homosexual or heterosexual activity or desire, the aim of which is erotic pleasure. This includes foreplay, as well as sexual intercourse. Also included are attempts to be sexually attractive to another, as well as being sexually attracted by another.

The range of possible scores, for any one theme, is -1 to 4 . Each story is rated for each theme, i.e., a report may have one or more themes present, but only one theme can be scored as the major or central theme.

(This scoring system is adapated from McClelland, Atkinson, Clark, and Lowe11, 1976.) 
$0 \quad$ Everydayish content--"I was thinking about typing my term paper," "I was in my kitchen rolling out pie dough," "The man was angry with his wife for forgetting about the dinner party," etc.

1 One element or image which is unusual--"I was thinking about typing my term paper on a banana peel," "I was in the kitchen rol1ing out pie dough with a screwdriver," "The man was angry with his wife for cooking the steaks over a candle flame," etc.

2 Two or more elements or images which are unusual--"I was thinking about typing my term paper on a banana peel and serving it up with nuts and cream," etc.

3 Magical or omnipotent thinking-- I was a giant waving my hand over an entire town. With each wave of my hand, the lights of the town became dimmer," "I was thinking about typing my term paper by just thinking the words and they just appeared on the page," etc.

Any criterion in the report which yields a higher score should define the judgment as the higher score. For example, one element or image which is unusual may be present along with magical or omnipotent thinking. The report would yield a score of 3 .

(This scale is adapted from Vogel's scale of regressivity. See Appendix C.) 


\section{APPENDIX I}

\section{RATING SCALE FOR VIVIDNESS--OMR AND TAT}

$0 \quad$ No content reported, feels mind was blank.

1 Conceptual content--"I was thinking about different shades of yellow, like a banana and a lemon are different yellows. I didn't really see the colors, I was just thinking about them being different." Also includes a statement of fact with no use of adjectives or adverbs.

2 Perceptual content, non-hallucinatory (subject knows that the image was not real)--"I was looking at a lemon and a banana and noticing the difference in shades of yellow. I knew that I was just making up these images, but it seemed easier to think about the differences in yellowness by imagining some examples." Also includes any story which uses 7 through 5 adjectives or adverbs.

3 Perceptual content, hallucinatory (subject believed, at the time of the experience, that the image was real)--"I was looking at a lemon and a banana and comparing the differences in shades of yellow. They seemed so real that I could reach out and touch them." (Also, see answer to question 6 in the OMR.) Also included are stories which use 6 or more adjectives or adverbs.

(This scale is adapted from the Dreamlike Fantasy Scale as it appears in Foulkes, Spear, and Symonds, 1966.) 
APPENDIX J

IMAGINAL PROCESSES INVENTORY SCALES

$\begin{array}{ll}\text { Scale } 1 & \text { Daydreaming Frequency } \\ \text { Scale 2 } & \text { Night-dreaming Frequency } \\ \text { Scale } 3 & \text { Absorption in Daydreaming } \\ \text { Scale } 4 & \text { Acceptance of Daydreaming } \\ \text { Scale } 5 & \text { Positive Reactions to Daydreams } \\ \text { Scale } 6 & \text { Frightened Reactions to Daydreams } \\ \text { Scale } 7 & \text { Visual Imagery in Daydreams } \\ \text { Scale } 8 & \text { Auditory Imagery in Daydreams } \\ \text { Scale } 9 & \text { Problem-solving in Daydreams } \\ \text { Scale 10 } & \text { Present Orientation in Daydreams } \\ \text { Scale 11 } & \text { Future Orientation in Daydreams } \\ \text { Scale 12 } & \text { Past Orientation in Daydreams } \\ \text { Scale 13 } & \text { Bizarre Improbable Daydreams } \\ \text { Scale 14 } & \text { Mind Wandering } \\ \text { Scale 15 } & \text { Achievement-oriented Daydreams } \\ \text { Scale 16 } & \text { Hallucinatory Vividness of Daydreams } \\ \text { Scale 17 } & \text { Fear of Failure in Daydreams } \\ \text { Scale 18 } & \text { Hostile Aggressive Daydreams } \\ \text { Scale 19 } & \text { Sexual Daydreams } \\ \text { Scale 20 } & \text { Heroic Daydreams } \\ \text { Scale 21 } & \text { Guilt Daydreams } \\ \text { Scale 22 } & \text { Interpersonal Curiosity } \\ \text { Scale 23 } & \text { Impersonal-mechanical Curiosity } \\ \text { Scale 24 } & \text { Boredom Susceptibility } \\ \text { Scale 25 } & \text { Mentation Rate } \\ \text { Scale 26 } & \text { Distractibility } \\ \text { Scale 27 } & \text { Need for External Stimulation } \\ \text { Scale 28 } & \text { Self-revelation }\end{array}$

(This list is presented as it appears in Huba, Segal, and Singer, 1977. Scale numbers have been added for clarity.) 


\section{APPENDIX K}

\section{COMPARISONS TO BE MADE BETWEEN CODED \\ CATEGORIES AND IPI SCALES}

1. Emotion Tone (ET) Scale 5--Positive Reaction to Daydreams

2. Outcome (0) Scale 17--Fear of Failure in Daydreams

3. Achievement $(\mathrm{ACH})$ Scale 15--Achievement-oriented Daydreams

4. Aggression (AG) Scale 18--Hostile Aggressive Daydreams

5. Sex $(S X) \quad$ Scale 19--Sexual Daydreams

6. Bizarreness (BZ) Scale 13--Bizarre Improbable Daydreams

7. Vividness (VV) Scale 16--Hallucinatory Vividness of Daydreams 